\title{
A Tax Plan for Endogenous Innovation*
}

\author{
M. M. Croce $^{\dagger}$ \\ A. G. Karantounias $\ddagger$ \\ S. Raymond ${ }^{\S}$ \\ L. Schmid 9
}

January 30, 2017

\begin{abstract}
In times when elevated government debt raises concerns about dimmer global growth prospects, we ask: How can the government provide incentives for innovation in a fiscally sustainable way? We address this question by examining the Ramsey problem of finding optimal tax and subsidy schemes in a model in which growth is endogenously sustained by risky innovation. We characterize the shadow value of growth and entry in the innovation sector. We find that a profit tax is required to replicate the first-best in order to balance the positive spillovers of innovative activity. At the second-best, the profit tax is designed to optimally respond to growth shocks above and beyond what is prescribed by the standard tax-smoothing incentives in economies with exogenous growth. The interplay of risk and innovation opens a new margin for optimal taxation.
\end{abstract}

Keywords: Innovation, endogenous growth, government debt, labor tax, subsidy, profit tax. JEL classification: E32; E62; H21; H63; O3.

* Preliminary. We are grateful to Marco Bassetto for his discussion and to conference participants at the 2017 AEA Meetings in Chicago. All errors are our own. The views expressed herein are those of the authors and not necessarily those of the Federal Reserve Bank of Atlanta or the Federal Reserve System.

${ }^{\dagger}$ Kenan-Flagler Business School, University of North Carolina at Chapel Hill. Email: mmc287@gmail.com.

${ }^{\ddagger}$ Research Department, Federal Reserve Bank of Atlanta. Email: anastasios.karantounias@atl.frb.org.

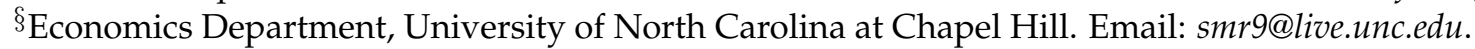

『The Fuqua School of Business, Duke University. Email: lukas.schmid@duke.edu . 


\section{Introduction}

Is the US economy heading towards a lost decade of productivity growth? It has been widely documented that the recovery from the 2008 Great Recession has been unusually slow, in spite of significant debt-financed government stimulus programs. At the same time, average annual productivity growth since 2011 has been a mere $1.1 \%$, not even half the roughly $2.5 \%$ average which boosted growth and welfare in the US since 1948. As pointed out recently by Prescott and Ohanian (2014), projecting this low growth rate over the next ten years would suggest an increase of US living standards by about $12 \%$ only, a figure reminiscent of the Japanese post-1990 lost decade slump.

In this paper, we examine what the government can do to facilitate productivity growth even when it is severely burdened by debt after a long lasting recession. Specifically, we follow Ramsey and look for optimal tax and subsidy schemes in an environment in which growth is driven and sustained by the entry of new innovative firms that facilitate the production of output, in the spirit of Romer (1990). As in Lucas and Stokey (1983), the government needs to find a sustainable way to finance stochastic expenditures with distortionary taxation. In contrast to Lucas and Stokey, the government uses both labor income and profits taxes to support both exogenous unproductive expenditures and subsidies to production. The resulting tax plan accounts for persistent exogenous shocks that can generate expansions and long-lasting recessions.

Our framework captures a number of elements that we think are at the heart of the current policy debate. In our stochastic environment, fiscally sustainable tax and subsidy schemes need to be intimately tied to both short- and medium-term cycles, so that fiscal prescriptions are allowed to vary both with current and projected growth. In order to relate to the current economic context, consider a government facing elevated debt burden in the aftermath of a great recession. Our analysis shows that such a situation restricts the set of feasible policies that can stimulate growth when distortionary tax instruments affect endogenous innovation prospects. Equivalently, fiscal tightness is associated with sluggish endogenous entry of innovative firms and poor long-term growth. This result is broadly consistent with the empirical 
observation in Prescott and Ohanian (2014) about US business creation: the current annual rate of new business creation is about 30 percent lower than it was at the beginning of the IT revolution.

In our model, new business creation through innovation reflects prospects of monopolistic rents after entry. Consistent with prior literature and many empirical studies, we allow for (i) a congestion in business creation, so that innovation is effectively subject to decreasing returns to scale, and (ii) a positive externality that makes business creation more efficient when the mass of startups in the economy is larger. The mass of incumbent firms determines final output jointly with labor input. In this simple economy, the endogenous growth rate thus reflects three margins, namely i) labor input, ii) the scale of incumbent firms, and iii) entry of new firms.

Given monopoly and externality distortions, as well as unproductive government expenditures, even with access to lump-sum taxation, a benevolent planner needs additional instruments to implement a first-best allocation. In the absence of lump-sum taxes, our Ramsey planner, in turn, faces the much harder problem of using distortionary tax instruments, such as labor and profit taxes, a production subsidy, as well as deficit financing, to implement a constrained optimal allocation.

Our results emphasize the importance of profit taxes in the presence of congestion externalities at entry, even when the government has access to lump-sum taxation. In this case, while the government can overcome monopolistic distortions by financing a production subsidy by lump-sum taxation, innovators fail to take into account the externality, resulting in excessive business creation. A profit tax restores the first-best allocation, featuring lower growth, but higher consumption, and thus welfare.

Profit taxation is optimal also in the presence of distortionary labor taxes and production subsidies. When restricting the governments tools to distortionary instruments, the second best features lower average growth than the first best and comes with substantial welfare losses relative to the first-best, no matter what the initial debt burden the government faces is. Intriguingly, however, in our stochastic environment, the presence and nature of risk has sig- 
nificant implications for the dynamics of optimal tax rates and growth. For example, a higher initial debt burden requires significantly more volatile tax rates, amplifying and propagating cycles both at the shorter (business cycle) and the medium horizon. Notably, most of the welfare losses from uncertainty are due to government expenditure risk. In the context of the present debate, this suggests that optimizing innovation and growth may come at the cost of endogenously higher risk.

Related Literature. Our work is a step towards bringing ideas of optimal taxation to bear on the literature on innovation-based endogenous growth in the context of the recent current debate. While both strands of literature are vast, few papers only recently started considering optimal tax and subsidy scheme in the contect of innovation, and ours is, to the best of our knowledge, the first to emphasize the role of macroeconomic risk and risky innovation.

Recent work includes Akcigit et al. (2016), who develop a Mirrleesian approach to optimal taxation in an estimated model with a rich firm heterogeneity. Aghion et al. (2013) revisit the classical Chamley result about capital taxation in a Schumpeterian growth framework with endogenous R\&D, while Jones et al. (1993) consider Ramsey taxation in a deterministic model in which growth results from investment in human capital. Atkeson and Burstein (2015) examine the medium term effects of changes in innovation policies across a variety of stationary growth models with rich cross-sectional heterogeneity. Our work differs from these papers by studying taxes and subsidies across cycles, in an environment with aggregate shocks.

Regarding optimal taxation in business cycle models, our work builds on the classic contribution of Lucas and Stokey (1983), and the business cycle analysis in Chari et al. (1994). Chugh and Ghironi (2010) examine Ramsey taxation in a model with endogenous product variety, similar to Melitz et al. (2012), but abstract away from innovation and endogenous growth. Relatedly, Karantounias (2013) analyzes optimal taxation and debt management with recursive utility, whereas Ferrière and Karantounias (2016) examine the emergence of austerity policies when there is ambiguity about the business cycle.

Our paper builds on Croce et al. (2011) and Croce et al. (2012), who examine the effects of 
fiscal policy in an endogenous growth similar to the one considered here, but focus on risksensitive fiscal rules, rather than the optimal schemes as in this paper.

\section{Economy}

Our model economy is based on a stochastic version of the economy of Romer (1990) with a rich government sector. In contrast to exogenous growth models as Lucas and Stokey (1983), growth is sustained through innovation in varieties of intermediate inputs.

Time is discrete and the horizon is infinite. The economy is populated by a representative household that trades in complete asset markets with the government. Lump-sum taxes are not available. We assume a complete tax system and allow three tax instruments to the government: a labor tax, a purchase subsidy and a profit tax in order to be able to affect three margins of interest: the labor supply margin, the intermediate input margin, and the profit margin that determines new varieties.

There are two types of shocks in the economy, a productivity shock $z_{t}$ and a government expenditure shock $\kappa_{t}$. Let $h_{t} \equiv\left(z_{t}, \kappa_{t}\right)$ denote the shocks at $t$ and let $h^{t} \equiv\left(h_{0}, h_{1}, \ldots, h_{t}\right)$ denote the partial history of shocks up to $t$ that occur with probability $\pi_{t}\left(h^{t}\right)$. The conditional expectation operator with respect to $\pi$ is denoted $E_{t}$. The initial realization of the shocks $h_{0}$ is known, so $\pi_{0}\left(h_{0}\right)=1$.

\subsection{Household}

The household enjoys utility from consumption $c_{t}\left(h^{t}\right)$, dislikes labor $L_{t}\left(h^{t}\right)$ and discounts the future with discount factor $\beta$. The notation denotes that these variables are measurable functions of the history $h^{t}$. There is one unit of time available, so leisure is $l_{t}\left(h^{t}\right) \equiv 1-L_{t}\left(h^{t}\right)$. The household gets paid a wage rate $w_{t}\left(h^{t}\right)$, pays linear labor income taxes at the rate $\tau_{t}\left(h^{t}\right)$ and buys shares of equity $Z_{t}\left(h^{t}\right)$ at price $Q_{t}\left(h^{t}\right)$, that provide dividends $D_{t}\left(h^{t}\right)$. The house-

hold trades also Arrow securities at the price $p_{t}\left(h_{t+1}, h^{t}\right)$. This is the price at $h^{t}$ of a security that gives one unit of consumption next period when the shock $h_{t+1}$ realizes and zero oth- 
erwise. The respective holdings are denoted as $b_{t+1}\left(h^{t+1}\right)$. The corresponding price of an Arrow-Debreu contract at $t=0$ is $q_{t}\left(h^{t}\right)$ with the normalization $q_{0} \equiv 1$.

The problem of the household is to choose $\left\{c_{t}\left(h^{t}\right), L_{t}\left(h^{t}\right), b_{t+1}\left(h^{t+1}\right), Z_{t}\left(h^{t}\right)\right\}_{t, h^{t}}$ to maximize

$$
\sum_{t=0}^{\infty} \beta^{t} \sum_{h^{t}} \pi_{t}\left(h^{t}\right) u\left(c_{t}\left(h^{t}\right), 1-L_{t}\left(h^{t}\right)\right)
$$

subject to

$$
\begin{aligned}
& c_{t}\left(h^{t}\right)+\sum_{h_{t+1}} p_{t}\left(h_{t+1}, h^{t}\right) b_{t+1}\left(h^{t+1}\right)+Q_{t}\left(h^{t}\right) Z_{t}\left(h^{t}\right) \leq\left(1-\tau_{t}\left(h^{t}\right)\right) w_{t}\left(h^{t}\right) L_{t}\left(h^{t}\right) \\
& +\left(Q_{t}\left(h_{t}\right)+D_{t}\left(h^{t}\right)\right) Z_{t-1}\left(h^{t-1}\right)+b_{t}\left(h^{t}\right)
\end{aligned}
$$

the non-negativity and feasibility constraints $c_{t}\left(h^{t}\right), Z_{t}\left(h^{t}\right) \geq 0, L_{t}\left(h^{t}\right) \in[0,1]$, given an initial level of debt or assets $b_{0}$ and initial equity shares $Z_{-1}=1$. The period utility function $u$ is assumed to be consistent with balanced growth restrictions. For the problem of the household to be well-defined, we need also the no-Ponzi-game condition

$$
\lim _{t \rightarrow \infty} \sum_{h^{t}} q_{t}\left(h^{t}\right)\left[Q_{t}\left(h^{t}\right) Z_{t}\left(h^{t}\right)+\sum_{h_{t+1}} p_{t}\left(h_{t+1}, h^{t}\right) b_{t+1}\left(h^{t+1}\right)\right] \geq 0
$$

The household is also subject to the no-arbitrage condition between Arrow securities and equity ${ }^{1}$

$$
Q_{t}\left(h^{t}\right)=\sum_{h_{t+1}} p_{t}\left(h_{t+1}, h^{t}\right)\left(Q_{t+1}\left(h^{t+1}\right)+D_{t+1}\left(h^{t+1}\right)\right) .
$$

\footnotetext{
${ }^{1}$ This condition will be also derived as a first-order condition of the household.
} 


\subsection{Production}

The production side of the economy consists of three sectors; a competitive final good sector, a monopolistic intermediate input sector and a competitive R\&D sector.

Final good. The final good $Y_{t}\left(h^{t}\right)$ is produced by labor $L_{t}\left(h^{t}\right)$ and a continuum of intermediate input varieties $i \in\left[0, A_{t}\left(h^{t-1}\right)\right]$. $A_{t}$ denotes the mass of varieties of inputs and is known one period in advance. The respective amount of input $i$ is denoted by $X_{t}\left(i, h^{t}\right)$. The production function of the final good takes the form

$$
Y_{t}\left(h^{t}\right)=F\left(L_{t}, X_{i t}, A_{t}\right)=z_{t} L_{t}\left(h^{t}\right)^{1-\alpha} \int_{0}^{A_{t}\left(h^{t-1}\right)} X_{t}\left(i, h^{t}\right)^{\alpha} d i
$$

where $\alpha \in(0,1)$ the share of intermediate inputs in the final good production. The production function is constant returns to scale with respect to labor $L_{t}$ and intermediate inputs $X_{i t}$, which, together with competitive factor pricing, leads to zero profits. The price of intermediate inputs is $P_{i t}$. The purchase of intermediate inputs is subsidized at rate $\tau_{t}^{x}\left(h^{t}\right)$. The problem of the firm is

$$
\max _{L_{t}, X_{i t}} Y_{t}-w_{t} L_{t}-\int_{0}^{A_{t}}\left(1-\tau_{t}^{x}\right) P_{i t} X_{i t} d i
$$

Profit maximization leads to equalization of factor prices to marginal products:

$$
\begin{gathered}
w_{t}=F_{L} \Rightarrow w_{t}=(1-\alpha) \frac{Y_{t}}{L_{t}} \\
\left(1-\tau_{t}^{x}\right) P_{i t}=F_{i} \Rightarrow X_{i t}=\left(\frac{\alpha z_{t}}{\left(1-\tau_{t}^{x}\right) P_{i t}}\right)^{\frac{1}{1-\alpha}} L_{t}
\end{gathered}
$$

Condition (5), which determines the demand of intermediate inputs, implies an elasticity of demand of $1 /(1-\alpha)$. 
Intermediate good sector. Each technology for an intermediate input is operated by a monopolist that faces the demand function (5). The monopolist uses one unit of final good to produce one unit of intermediate input $X_{i t}$. His problem is to choose $P_{i t}$ to maximize profits

$$
\Pi_{i t}=P_{i t} X_{i t}-X_{i t}
$$

subject to the demand function (5).

R\&D sector. New varieties of intermediate inputs are created in the R\&D sector. After developing a new variety, the innovators sell at the end of the period a patent on it at a competitive market. From next period on, the patent can be used by a monopolist of the intermediate input sector. Each new variety survives for sure the first period. After that, it becomes obsolete with probability $\delta \in(0,1)$ every period. Monopoly profits are taxed at rate $\tau_{t}^{\pi}\left(h^{t}\right)$. Under these assumptions, the present value of the profits of the monopolist is

$$
V_{i t}=\left(1-\tau_{t}^{\pi}\right) \Pi_{i t}+(1-\delta) E_{t} \Lambda_{t+1} V_{i, t+1}
$$

where $\Lambda_{t+1}$ the stochastic discount factor. Let $1 / \vartheta_{t}$ denote the cost of producing one new variety in units of final good. The free-entry condition in the R\&D sector equates this cost to the expected present value of profits,

$$
\frac{1}{\vartheta_{t}}=E_{t} \Lambda_{t+1} V_{i, t+1}
$$

The free-entry condition (7) determines the growth rate in the economy by determining the amount of investment in R\& D. In particular, let $S_{t}\left(h^{t}\right)$ denote the amount of R\&D investment in units of the final good. Then, the mass of varieties evolves as 


$$
A_{t+1}\left(h^{t}\right)=(1-\delta) A_{t}\left(h^{t-1}\right)+\vartheta_{t}\left(h^{t}\right) S_{t}\left(h^{t}\right),
$$

where the initial mass of varieties $A_{0}$ is given. The growth rate in this economy is given by $A_{t+1} / A_{t}$

We assume that the marginal rate of transformation $\vartheta_{t}$ depends on the research intensity $S_{t} / A_{t}, \vartheta_{t}=\vartheta\left(S_{t} / A_{t}\right)$. The individual innovators are small and do not take this type of dependence into account, leading to an externality in the innovation process. In particular, we assume that

$$
\vartheta_{t}=\chi\left(\frac{S_{t}}{A_{t}}\right)^{\eta-1}, \eta \in(0,1)
$$

The parameter $\eta$ captures the elasticity of new varieties with respect to $R \& D$ investment. The formulation in (9) follows Comin and Gertler (2006), and captures two elements: negative congestion externalities in the R\&D sector $(\partial \vartheta / \partial S<0)$ and positive spillover externalities coming from an increase in the mass of varieties, $(\partial \vartheta / \partial A>0)$. These externalities are shut off when $\eta=1$, which implies a constant marginal rate of transformation, $\vartheta=\chi$.

\subsection{Government, stock market and equilibrium}

Government. We assume that government expenditures grow at the same rate as varieties and set $g_{t}\left(h^{t}\right)=\kappa_{t} A_{t}\left(h^{t-1}\right)$, in order to have a balanced growth path where government expenditures are relevant. Thus, $\kappa_{t}$ is the fiscal shock in the stationary version of our economy. The government issues state-contingent debt and uses three instruments, the labor tax $\tau_{t}$, the input purchase subsidy $\tau_{t}^{x}$ and the profit tax $\tau_{t}^{\pi}$. The dynamic government budget constraint reads 


$$
\begin{aligned}
b_{t}\left(h^{t}\right)= & \tau_{t}\left(h^{t}\right) w_{t}\left(h^{t}\right) L_{t}\left(h^{t}\right)+\tau_{t}^{\pi}\left(h^{t}\right) \int_{0}^{A_{t}} \Pi_{i t} d i-\tau_{t}^{x}\left(h^{t}\right) \int_{0}^{A_{t}} P_{i t} X_{i t} d i-g_{t} \\
& +\sum_{h_{t+1}} p_{t}\left(h_{t+1}, h^{t}\right) b_{t+1}\left(h^{t+1}\right) .
\end{aligned}
$$

Stock market. We close the model by specifying aggregate dividends. We assume that the stock market values all production sectors, and therefore aggregate dividends are equal to the the aggregate after-tax profits of the intermediate input sector, minus investment in $R \& D$,

$$
D_{t}\left(h^{t}\right)=\left(1-\tau_{t}^{\pi}\left(h^{t}\right)\right) \int_{0}^{A_{t}} \Pi_{i t} d i-S_{t}\left(h^{t}\right)
$$

Market equilibrium. The definition of equilibrium is standard. The equilibrium consists of a government policy $\left\{\tau, \tau^{x}, \tau^{\pi}, b, g\right\}$, an allocation $\left\{c, L, S, X_{i, i \in[0, A]}, b, Z\right\}$, prices $\left\{p, w, P_{i, i \in[0, A]}, Q\right\}$, dividends $\{D\}$, and a mass of varieties $\{A\}$ such that: 1) Given prices $\{p, w, Q\}$, dividends $\{D\}$ and government policy $\{\tau\},\{c, L, b, Z\}$ solves the household's problem 2) Given $\left\{w, P_{i, i \in[0, A]}\right\}$

and subsidies $\left\{\tau^{x}\right\}$ the final good firm maximizes profits 3) Given subsidies $\left\{\tau^{x}\right\}$ and profit taxes $\left\{\tau^{\pi}\right\}$, the monopolist sets prices $P_{i}$ to maximize profits 4 ) The free-entry condition (7) holds, varieties accumulate according to (8) and aggregate dividends satisfy (11) 5) Prices and government policy are such that the resource and the government budget constraint (10) hold and the equity market clears, $Z_{t}\left(h^{t}\right)=1, \forall t, h^{t}$. The resource constraint reads

$$
c_{t}\left(h^{t}\right)+\int_{0}^{A_{t}\left(h^{t-1}\right)} X_{t}\left(i, h^{t}\right) d i+S_{t}\left(h^{t}\right)+g_{t}\left(h^{t}\right)=Y_{t}\left(h^{t}\right)
$$

\subsection{Analysis of market equilibrium}

Optimality conditions of household. The labor supply decision is governed by the typical equalization of the marginal rate of substitution of consumption and leisure to the after-tax wage, 


$$
\frac{u_{l}\left(h^{t}\right)}{u_{c}\left(h^{t}\right)}=\left(1-\tau_{t}\left(h^{t}\right)\right) w_{t}\left(h^{t}\right)
$$

The respective demand for labor is determined by (4), which equates the wage to the marginal product of labor, $w_{t}=F_{L}$. The first-order condition with respect to Arrow securities and equity are

$$
\begin{aligned}
p_{t}\left(h_{t+1}, h^{t}\right) & =\beta \pi_{t+1}\left(h_{t+1} \mid h^{t}\right) \frac{u_{c}\left(h^{t+1}\right)}{u_{c}\left(h^{t}\right)} \\
Q_{t}\left(h^{t}\right) & =\beta \sum_{h_{t+1}} \pi_{t+1}\left(h_{t+1} \mid h^{t}\right) \frac{u_{c}\left(h^{t+1}\right)}{u_{c}\left(h^{t}\right)}\left[Q_{t+1}\left(h^{t+1}\right)+D_{t+1}\left(h^{t+1}\right)\right],
\end{aligned}
$$

which imply the no-arbitrage condition (2) and the standard stochastic discount factor for time-additive expected utility, $\Lambda_{t+1} \equiv \beta \frac{u_{c, t+1}}{u_{c t}}$.

Equilibrium production. Due to the constant demand elasticity, each monopolist charges a price that is a constant markup over the unitary marginal cost, $P_{i t}=P^{*}=\frac{1}{\alpha}>1 \forall i$. Since the optimal price and the subsidy do not depend on $i$, the equilibrium intermediate inputs and profits are the same for each variety,

$$
\begin{aligned}
X_{i t} & =X_{t}=\left(\frac{\alpha z_{t}}{P^{*}\left(1-\tau_{t}^{x}\right)}\right)^{\frac{1}{1-\alpha}} L_{t} \forall i \\
\Pi_{i t} & =\Pi_{t}^{*}=\left(P^{*}-1\right) X_{t}
\end{aligned}
$$

The resource constraint simplifies to

$$
c_{t}+S_{t}+A_{t} X_{t}+g_{t}=Y_{t}
$$


where gross output becomes $Y_{t}=z_{t} A_{t} L_{t}^{1-\alpha} X_{t}^{\alpha}$. We can express output as a linear function of labor, and total intermediate inputs as function of output,

$$
\begin{aligned}
Y_{t} & =\left(\frac{\alpha}{P^{*}\left(1-\tau_{t}^{x}\right)}\right)^{\frac{\alpha}{1-\alpha}} z_{t}^{\frac{1}{1-\alpha}} A_{t} L_{t} \\
A_{t} X_{t} & =\frac{\alpha Y_{t}}{\left(1-\tau_{t}^{x}\right) P^{*}}
\end{aligned}
$$

Surplus. Using (20) we get the following relationships for aggregate profits and aggregate subsidies $T_{t}^{x}$,

$$
\begin{aligned}
A_{t} \Pi_{t} & =\frac{P^{*}-1}{\left(1-\tau_{t}^{x}\right) P^{*}} \alpha Y_{t} \\
T_{t}^{x} & =\tau_{t}^{x} A_{t} P^{*} X_{t}=\frac{\tau_{t}^{x}}{1-\tau_{t}^{x}} \alpha Y_{t}
\end{aligned}
$$

Using (4) and (21-22), allows us to write the government surplus as

$$
\mathcal{S}_{t} \equiv \tau_{t} w_{t} L_{t}+\tau_{t}^{\pi} A_{t} \Pi_{t}-T_{t}^{x}-g_{t}=\left[(1-\alpha) \tau_{t}+\tau_{t}^{\pi} \frac{P^{*}-1}{\left(1-\tau_{t}^{x}\right) P^{*}} \alpha-\frac{\tau_{t}^{x}}{1-\tau_{t}^{x}} \alpha\right] Y_{t}-g_{t}
$$

Growth and R\&D returns. We have $V_{i t}=V_{t}, \forall i$. Use (6) and (7) in order to express the present value of profits as

$$
V_{t}=\left(1-\tau_{t}^{\pi}\right) \Pi_{t}+\frac{1-\delta}{\vartheta_{t}}
$$

By updating the above relationship one period (i.e. by taking into account that in the future the present value of profits will be equal to the cost of new varieties) we can rewrite the freeentry condition as a condition that prices returns to R\&D: 


$$
1=E_{t} \Lambda_{t+1} R_{t+1}^{R D}
$$

where

$$
R_{t+1}^{R D} \equiv \frac{\vartheta_{t}}{\vartheta_{t+1}}\left[1-\delta+\vartheta_{t+1}\left(1-\tau_{t+1}^{\pi}\right) \Pi_{t+1}\right]
$$

the return on $R \& D .^{2}$

\section{First-best problem}

The first-best entails three margins: the labor supply margin, the intermediate input margin and the new variety margin that determines the growth rate in the economy.

Problem 1. The first-best problem is to choose $\left\{c_{t}\left(h^{t}\right), L_{t}\left(h^{t}\right), X_{t}\left(i, h^{t}\right), S_{t}\left(h^{t}\right), A_{t+1}\left(h^{t}\right)\right\} t_{t, h^{t}}$ to maximize

$$
\sum_{t=0}^{\infty} \beta^{t} \sum_{h^{t}} \pi_{t}\left(h^{t}\right) u\left(c_{t}\left(h^{t}\right), 1-L_{t}\left(h^{t}\right)\right)
$$

subject to the resource constraint (12) and the law of motion (8), given $\left(h_{0}, A_{0}\right)$.

\subsection{Labor supply and intermediate inputs}

Labor supply margin. At the first-best we get the standard intratemporal efficiency condition that equalizes the marginal rate of substitution of consumption and leisure to the marginal

\footnotetext{
${ }^{2}$ Equivalent definitions of the return are $R_{t+1}^{R D}=\frac{V_{t+1}}{\vartheta_{t}^{-1}}=\frac{(1-\delta) V_{t+1}}{V_{t}-\left(1-\tau_{t}^{\pi}\right) \Pi_{t}}$.
} 
product of labor,

$$
\frac{u_{l}}{u_{c}}=F_{L}=(1-\alpha) \frac{Y_{t}}{L_{t}}
$$

In the market equilibrium instead we have distortionary labor taxation.

Intermediate input margin. The second margin is that intermediate inputs have to be employed up so that their marginal product is equal to their marginal cost, which is unity,

$$
F_{i}=1, \forall i
$$

This leads to the same use of inputs across $i$ and $X_{t}=\left(\alpha z_{t}\right)^{\frac{1}{1-\alpha}} L_{t}, Y_{t}=\alpha^{\frac{\alpha}{1-\alpha}} z_{t}^{\frac{1}{1-\alpha}} A_{t} L_{t}$. Note furthermore that $A_{t} X_{t}=\alpha Y_{t}$, thus the net output that goes to private consumption, government consumption and R\&D investment is $(1-\alpha) Y_{t}$.

Condition (27) contrasts to the market condition $F_{i}=\left(1-\tau_{t}^{x}\right) P^{*}$. Assume for example that there are no subsidies, $\tau_{t}^{x}=0$. Then, $F_{i}=P^{*}=1 / \alpha>1$. Thus, monopoly power leads to a high price and therefore to limited demand of intermediate input $X_{t}$ and therefore to a marginal product of input $i$ that is too high. This is the main source of inefficiency in models of endogenous growth à la Romer (1990).

\subsection{Optimal growth}

The third margin that characterizes the first-best is involving R\&D investment and the optimal expansion of varieties. Let $\lambda_{t}$ denote the multiplier on the resource constraint and $\mu_{t}$ the multiplier on the law of motion of varieties. The first-order condition with respect to $S_{t}\left(h^{t}\right)$, takes the form

$$
\lambda_{t}=\mu_{t} \vartheta_{t}\left(1-\epsilon_{t}\right)
$$


where $\epsilon_{t} \equiv-\frac{\vartheta_{t}^{\prime}}{\vartheta_{t}} S_{t} A_{t}>0$ denotes the elasticity of cost with respect to research intensity. The larger it is, the more costly it is to produce one additional variety. The optimality condition (28) shows that the shadow value of $S_{t}$ has to be adjusted downwards in comparison to the shadow value of the final good, which is equal to the marginal utility of consumption, $\lambda_{t}=u_{c t}$, due to the negative effect of an increase in research intensity. For the power specification in (9) we have $\epsilon_{t}=1-\eta$, so $\lambda_{t}=\eta \mu_{t} \vartheta_{t}$.

The optimality condition with respect to the mass of varieties $A_{t+1}$ takes the form

$$
\mu_{t}=\beta E_{t} \lambda_{t+1} \underbrace{\left[\frac{Y_{t+1}}{A_{t+1}}-X_{t+1}-\kappa_{t+1}\right]}_{\text {net benefit of a new variety }}+\beta E_{t} \mu_{t+1}[1-\delta+\underbrace{\vartheta_{t+1}(1-\eta) \frac{S_{t+1}}{A_{t+1}}}_{\text {increase in } \vartheta \text { due to increase in } A_{t+1}}]
$$

Inventing a new variety has a benefit in terms of final good produced, $Y_{t} / A_{t}$, and a cost in terms of the amount $X_{t}$ that is used in the production of the final output and in terms of wasteful government expenditures $\kappa_{t}$. This net benefit is captured by the first-term in the right-hand side. The second term in the right-hand side captures the probability that this new variety will survive next period, together with the positive spillover effect of new varieties.

Use (28) and the fact that $\lambda_{t}=u_{c t}$ to finally get

$$
1=\beta E_{t} \frac{u_{c, t+1}}{u_{c t}} R_{t+1}^{s o c}
$$

where

$$
R_{t+1}^{s o c} \equiv \frac{\vartheta_{t}}{\vartheta_{t+1}}\left[1-\delta+\vartheta_{t+1}\left\{\eta\left(\frac{Y_{t+1}}{A_{t+1}}-X_{t+1}-\kappa_{t+1}\right)+(1-\eta) \frac{S_{t+1}}{A_{t+1}}\right\}\right]
$$

Contrast (30) with the market free-entry condition that prices returns to R\&D (24). The discrepancies come from three differences in the private return to $R \& D, R_{t+1}^{R D}$, from the social return to $R \& D, R_{t+1}^{s o c}$. First, the planner is considering a weighted average of the net benefit of a new variety and the cost reduction that this implies, due to the positive spillovers. In the 
calculation of the net benefit, the planner is taking into account that is costly to convert final goods to new varieties due to the congestion externalities. Both the congestion externality and the positive spillovers are not taken into account at the market equilibrium. Second, at the market equilibrium agents do not take into account that an expansion in varieties increases also government expenditures, which are a negative wealth shock to the economy since they provide no utility. Third, the market condition depends on after-tax profits of a new variety, which are not necessarily the same as the output benefit of a new variety $Y_{t} / A_{t}-X_{t}$.

By correcting the monopoly distortion through a subsidy and setting the profit tax in such a way so that the private and social returns to $R \& D$ are equated, we can implement the first-best allocation as a market equilibrium.

Proposition 1. The first-best allocation can be implemented as a market equilibrium with lump-sum taxes, a purchase subsidy $\tau_{t}^{x}=1-\alpha\left(\Rightarrow\left(1-\tau_{t}^{x}\right) P^{*}=1\right)$, and a profit tax that equates the social return $R^{s o c}$ to the private return $R^{R D}$

$$
\tau_{t}^{\pi}=\eta \frac{g_{t}}{(1-\alpha) Y_{t}}+(1-\eta)\left[1-\frac{S_{t}}{(1-\alpha) Y_{t}}\right]
$$

Proof. Set the profit tax so that $R_{t}^{R D}=R_{t}^{s o c}$. This implies that

$$
\left(1-\tau_{t}^{\pi}\right) \Pi_{t}=\eta\left(\frac{Y_{t}}{A_{t}}-X_{t}-\kappa_{t}\right)+(1-\eta) \frac{S_{t}}{A_{t}}
$$

Use now the fact that under the optimal subsidy we have $\Pi_{t}=Y_{t} / A_{t}-X_{t}=(1-\alpha) Y_{t} / A_{t}$, simplify and rearrange to get (32).

The profit tax that implements the first-best (32) corrects for excessive growth in the market equilibrium coming from wasteful government expenditures and the congestion externalities (that dominate the positive spillovers). It is a weighted average of the share of government expenditures in net output and the share of private and government consumption in net output (since $1-\frac{S_{t}}{(1-\alpha) Y_{t}}=\frac{c_{t}}{(1-\alpha) Y_{t}}+\frac{g_{t}}{(1-\alpha) Y_{t}}$ ). When there are no government expenditures and 
no externalities, $g_{t}=0, \eta=1$, the profit tax is not necessary and just correcting the static monopoly distortion is sufficient to achieve the first-best.

\section{Optimal fiscal policy}

In contrast to the previous section, we will now assume away lump-sum taxes and analyze the second-best problem of a Ramsey planner that maximizes the utility of the representative household under commitment. We follow the primal approach of Lucas and Stokey (1983) and simplify the optimality conditions of the market equilibrium by eliminating prices and tax rates whenever possible.

\subsection{Implementability constraints}

Condition (1) holds with equality in equilibrium. Use this fact together with the no-arbitrage condition (2) and the initial condition $Z_{-1}=1$ to get the household's intertemporal budget constraint,

$$
\sum_{t=0}^{\infty} \sum_{h^{t}} q_{t}\left(h^{t}\right)\left(c_{t}\left(h^{t}\right)-\left(1-\tau_{t}\left(h^{t}\right)\right) w_{t}\left(h^{t}\right) L_{t}\left(h^{t}\right)\right)=b_{0}+Q_{0}+D_{0}
$$

We can replace $Q_{0}$ with the present value of dividends. Solve (2) forward and impose the asymptotic condition $\lim _{t \rightarrow \infty} \sum_{h^{t}} q_{t}\left(h^{t}\right) Q_{t}\left(h^{t}\right)=0$ to get

$$
Q_{0}+D_{0}=\sum_{t=0}^{\infty} \sum_{h^{t}} q_{t}\left(h^{t}\right) D_{t}\left(h^{t}\right)
$$

Therefore the household's budget constraint in equilibrium can be written as 


$$
\sum_{t=0}^{\infty} \sum_{h^{t}} q_{t}\left(h^{t}\right)\left(c_{t}\left(h^{t}\right)-\left(1-\tau_{t}\left(h^{t}\right)\right) w_{t}\left(h^{t}\right) L_{t}\left(h^{t}\right)-D_{t}\left(h^{t}\right)\right)=b_{0}
$$

Note that the term in the parenthesis, i.e. consumption minus after-tax labor income minus aggregate dividends is equal in equilibrium to the government surplus $\mathcal{S}_{t}$, a fact which makes redundant the government budget constraint in equilibrium. Use now the fact that ArrowDebreu prices are $q_{t}=\beta^{t} \pi_{t} \frac{u_{c t}}{u_{c 0}}$ and (13) to eliminate prices and after-tax wages and get the implementability constraint

$\sum_{t=0}^{\infty} \sum_{h^{t}} \beta^{t} \pi_{t}\left(h^{t}\right)\left(u_{c}\left(h^{t}\right) c_{t}\left(h^{t}\right)-u_{l}\left(h^{t}\right) L_{t}\left(h^{t}\right)-u_{c}\left(h^{t}\right)\left[A_{t}\left(h^{t-1}\right)\left(1-\tau_{t}^{\pi}\left(h^{t}\right)\right) \Pi_{t}\left(h^{t}\right)-S_{t}\left(h^{t}\right)\right]\right)=u_{c 0} b_{0}$.

In formulating the Ramsey problem, we have to take into account the present value of profits $V_{t}$ and the free-entry condition (7). However, we can eliminate $V_{t}$ from the constraints and use only the period-by-period condition (24). There is no information lost by this substitution. Furthermore, without loss of generality, we are going to assume that the profit tax is known one period in advance, so $\tau_{t+1}^{\pi}=\tau_{t+1}^{\pi}\left(h^{t}\right)$. The initial profit tax $\tau_{0}^{\pi}$ acts as lump-sum tax and is given.

\subsection{Ramsey problem}

Problem 2. The Ramsey planner chooses $\left\{c_{t}\left(h^{t}\right), L_{t}\left(h^{t}\right), S_{t}\left(h^{t}\right), A_{t+1}\left(h^{t}\right), Y_{t}\left(h^{t}\right), L_{t}\left(h^{t}\right), \tau_{t}^{x}\left(h^{t}\right), \tau_{t+1}^{\tau}\left(h^{t}\right)\right\}_{t, h^{t}}$ to maximize

$$
\sum_{t=0}^{\infty} \beta^{t} \sum_{h^{t}} \pi_{t}\left(h^{t}\right) u\left(c_{t}\left(h^{t}\right), 1-L_{t}\left(h^{t}\right)\right)
$$

subject to 


$$
\begin{aligned}
& \sum_{t=0}^{\infty} \sum_{h^{t}} \beta^{t} \pi_{t}\left(h^{t}\right)\left[u_{c}\left(h^{t}\right) c_{t}\left(h^{t}\right)-u_{l}\left(h^{t}\right) L_{t}\left(h^{t}\right)\right. \\
& \left.-u_{c}\left(h^{t}\right)\left(A_{t}\left(h^{t-1}\right)\left(1-\tau_{t}^{\pi}\left(h^{t-1}\right)\right)\left(P^{*}-1\right) X_{t}\left(h^{t}\right)-S_{t}\left(h^{t}\right)\right)\right]=u_{c}\left(h_{0}\right) b_{0} \\
& c_{t}\left(h^{t}\right)+A_{t}\left(h^{t-1}\right) X_{t}\left(h^{t}\right)+S_{t}\left(h^{t}\right)+\kappa_{t} A_{t}\left(h^{t-1}\right)=Y_{t}\left(h^{t}\right) \\
& A_{t+1}\left(h^{t}\right)=\vartheta\left(\frac{S_{t}\left(h^{t}\right)}{A_{t}\left(h^{t-1}\right)}\right) S_{t}\left(h^{t}\right)+(1-\delta) A_{t}\left(h^{t-1}\right) \\
& u_{c}\left(c_{t}\left(h^{t}\right), 1-L_{t}\left(h^{t}\right)\right)=\beta \sum \pi_{h_{t+1}}\left(h_{t+1} \mid h^{t}\right) u_{c}\left(c_{t+1}\left(h^{t+1}\right), 1-L_{t+1}\left(h^{t+1}\right)\right) \\
& \cdot \vartheta\left(\frac{S_{t}\left(h^{t}\right)}{A_{t}\left(h^{t-1}\right)}\right)\left[\left(1-\tau_{t+1}^{\pi}\left(h^{t}\right)\right)\left(P^{*}-1\right) X_{t+1}\left(h^{t+1}\right)+\frac{1-\delta}{\vartheta\left(\frac{S_{t+1}\left(h^{t+1}\right)}{A_{t+1}\left(h^{t}\right)}\right)}\right]
\end{aligned}
$$

where $X_{t}$ and $Y_{t}$ are given by the formulas (16) and (19) respectively, and $\left(h_{0}, b_{0}, A_{0}, \tau_{0}^{\pi}\right)$ given.

The planner faces as constraints the intertemporal budget constraint of the household (34), the resource constraint (35), the law of motion of the mass of varieties (36), and the pricing equation (37) that we derived from the free-entry condition at the R\&D sector. The endogenous growth elements show up as aggregate dividends (in 34), the law of motion (36) and especially the forward-looking condition (37).

\section{Ramsey analysis}

Assign multipliers $\Phi$ on the implementability constraint (34), $\beta^{t} \pi_{t}\left(h^{t}\right) \lambda_{t}\left(h^{t}\right)$ on the resource constraint (35), $\beta^{t} \pi_{t}\left(h^{t}\right) \mu_{t}\left(h^{t}\right)$ on the law of motion (36), and $\beta^{t} \pi_{t}\left(h^{t}\right) \rho_{t}\left(h^{t}\right)$ on the pricing equation of R\&D returns (37). The initial condition on the multiplier on the forward-looking constraint is zero, $\rho_{-1} \equiv 0$, because the Ramsey planner is not constrained by any past promises at $t=0$.

\subsection{Profit tax}

Consider first the optimality condition with respect to the profit tax $\tau_{t}^{\pi}$. This takes the form 


$$
\underbrace{\Phi}_{\text {MB of relaxing the budget }}=\underbrace{\frac{\rho_{t-1} \vartheta_{t-1}}{A_{t}}}_{\text {MC of reducing profits }}, t \geq 1
$$

Equation (38) has a marginal benefit and marginal cost interpretation. An increase in tax revenues from profits relaxes the government budget constraint, which has shadow value $\Phi>0$ at the second-best. This marginal benefit is equated to the marginal cost of profit taxation: an increase in profit taxes reduces the expected discounted profits at $t-1$ and reduces entry. This is captured by the shadow value of free-entry condition (24) at $t-1, \rho_{t-1}$.

The first-best is captured by $\Phi=\rho_{t}=0, \forall t$. Condition (38) makes clear also why we take as given the profit tax at $t=0$. A planner that chose $\tau_{0}^{\pi}$ would face only the marginal benefit of relaxing the government budget and no marginal cost, since there are no past promises to abide to, $\rho_{-1}=0$. Thus, the profit tax would act as a lump-sum tax and, if the tax base is sufficiently large, we would achieve the first-best, $\Phi=0$.

\subsection{Optimal subsidy}

Consider now the optimal subsidy for $t \geq 0$. The optimality condition takes the form

$$
\underbrace{\frac{\partial Y_{t}}{\partial \tau_{t}^{x}}-A_{t} \frac{\partial X_{t}}{\partial \tau_{t}^{x}}}_{\text {net output benefit }}=\left[\Phi A_{t}-\rho_{t-1} \vartheta_{t-1}\right] \frac{u_{c t}}{\lambda_{t}}\left(1-\tau_{t}^{\pi}\right)\left(P^{*}-1\right) \frac{\partial X}{\partial \tau_{t}^{x}}
$$

The left-hand side denotes the net output effect of a subsidy to the production of the final good by subsidizing the purchase of intermediate inputs. This would be the only relevant margin in the first-best. Subsidies though are costly at the second-best because they have to be financed by distortionary taxation, but they can be beneficial because they increase the present value of profits and increase entry. These marginal costs and benefits are at the right-hand side of (39) and are equal to zero for $t \geq 1$, as we saw from the analysis of the profit tax. Thus, we 
get

Proposition 2. Assume the availability of a profit tax to the Ramsey planner. Then

1. The optimal subsidy of the Ramsey problem for $t \geq 1$ corrects only the monopolist distortion, $\tau_{t}^{x}=1-\alpha, t \geq 1$

2. When $\tau_{t}^{x}=1-\alpha$, aggregate subsidies, profits and labor income are equal to net output,

$$
T_{t}^{x}=A_{t} \Pi_{t}=w_{t} L_{t}=Y_{t}-A_{t} X_{t}=(1-\alpha) Y_{t}
$$

Proof. Note that $\frac{\partial Y_{t}}{\partial \tau_{t}^{x}}=\frac{\alpha Y_{t}}{1-\alpha}\left(1-\tau_{t}^{x}\right)^{-1}$ and $\frac{\partial X_{t}}{\partial \tau_{t}^{x}}=\frac{X_{t}}{1-\alpha}\left(1-\tau_{t}^{x}\right)^{-1}$. Thus, the net output benefit is $\frac{\left(1-\tau_{t}^{x}\right)^{-1}}{1-\alpha}\left[\alpha Y_{t}-A_{t} X_{t}\right]=0$. Thus, aggregate inputs are $A_{t} X_{t}=\alpha Y_{t}$, which by (20) implies that $\left(1-\tau_{t}^{x}\right) P^{*}=1$. Under the optimal subsidy, equations (21) and (22) deliver the second part of the proposition.

Proposition 2 brings to mind the production efficiency results of Diamond and Mirrlees (1971). Note the importance of a complete tax system. In the absence of a way to affect the profit margin, (38) would not hold. Then it easy to see that if the shadow cost of financing the subsidy is larger (smaller) than the benefit of increasing entry, $\Phi>(<) \rho_{t-1} \vartheta_{t-1} / A_{t}$, then the subsidy is smaller (larger) than at the first-best, $\tau_{t}^{x}<(>) 1-\alpha$.

\subsection{Optimal labor tax}

Let consumption minus after-tax labor income in marginal utility terms be denoted as

$$
\Omega(c, L) \equiv u_{c}(c, 1-L) c-u_{l}(c, 1-L) L
$$

The first-order condition with respect to $c_{t}, t \geq 1$ is

$$
u_{c t}+\underbrace{\Phi \Omega_{c t}}_{\text {effect on net consumption }}-\underbrace{u_{c c t}\left[\Phi D_{t}+\rho_{t}-\rho_{t-1} R_{t}^{R D}\right]}_{\text {devaluation of } D_{t} \text { and effect on (24) }}=\lambda_{t} .
$$


An increase in consumption has the following effects. First, it increases utility, $u_{c}>0$. Second, it has an effect on the government surplus, by affecting consumption net of after-tax labor income and by devaluing dividends in marginal utility units. Third, it decreases marginal utility and therefore the way how the period return of a patent is priced in (24). A decrease in marginal utility has two effects: it increases the valuation of next periods profits and return, (which is captured by $\rho_{t}$ ) and it decreases the valuation of current period's return $R_{t}^{R D}$ at the previous period, captured by $\rho_{t-1}$. This is a problem under commitment, i.e. the planner has to respect its past promises of marginal utility, as captured by their shadow value $\left(\rho_{t-1}\right)$. However, the total effect of dividend devaluation and manipulating the forward-looking equation (24) is zero, due again to the availability of the profit tax.

Lemma 1. Assume the availability of a profit tax to the Ramsey planner. Then,

1. The change in the shadow value of the pricing equation $\rho_{t}$ (adjusted by the surviving mass of varieties) is

$$
\rho_{t}-\rho_{t-1} \frac{\vartheta_{t-1}}{\vartheta_{t}}(1-\delta)=\Phi S_{t}, t \geq 1
$$

2. The total effect of changing the value of dividends and the present value of profits is zero,

$$
\Phi D_{t}+\rho_{t}-\rho_{t-1} R_{t}^{R D}=0, t \geq 1
$$

Proof. See Appendix.

Using lemma 1 leads to

$$
u_{c t}+\Phi \Omega_{c t}=\lambda_{t}
$$


which is actually the same optimality condition as in an economy with exogenous growth. Similar interpretations hold for the first-order condition with respect to labor for $t \geq 1$ :

$$
\begin{aligned}
& u_{l t}-\underbrace{\Phi \Omega_{L t}}_{\text {effect on net consumption }}-\underbrace{u_{c l t}\left[\Phi D_{t}+\rho_{t}-\rho_{t-1} R_{t}^{R D}\right]}_{\text {zero due to lemma 1 }}+\underbrace{\left(\Phi A_{t}-\rho_{t-1} \vartheta_{t-1}\right)}_{\text {zero due to (38) }} u_{c t}\left(1-\tau_{t}^{\pi}\right) \frac{\Pi_{t}}{L_{t}} \\
& =\lambda_{t} \underbrace{\left[\frac{Y_{t}}{L_{t}}-\frac{A_{t} X_{t}}{L_{t}}\right]}_{\text {net output benefit }}
\end{aligned}
$$

which leads to

$$
u_{l t}-\Phi \Omega_{L t}=\lambda_{t}\left[\frac{Y_{t}}{L_{t}}-\frac{A_{t} X_{t}}{L_{t}}\right]
$$

In comparison to the analysis of (41), there is an additional effect that comes from the increase of profits due to an increase in labor. Higher profits tighten the government budget but increase entry. When the profit tax is optimally chosen, these marginal costs and benefits are equal though, leading to the simplified optimality condition (45). The above optimality conditions allow us to derive an expression for the optimal labor tax.

Proposition 3. Assume the availability of a profit tax to the Ramsey planner. Then, the optimal labor tax at $t \geq 1$ is

$$
\tau_{t}=\frac{\Phi\left(\varepsilon_{c c}+\varepsilon_{c L}+\varepsilon_{L L}+\varepsilon_{L c}\right)}{1+\Phi\left(1+\varepsilon_{L L}+\varepsilon_{L c}\right)}
$$

where $\varepsilon_{c c} \equiv-u_{c c} c / u_{c}, \varepsilon_{c L} \equiv u_{c l} L / u_{c}, \varepsilon_{L L} \equiv-u_{l l} L / u_{l}, \varepsilon_{L c} \equiv u_{c l} c / u_{l}$ own and cross elasticities of the marginal utility of consumption and the marginal disutility of labor.

Proof. See the Appendix.

Note that this formula is exactly the same as in the exogenous growth economies of Lucas and Stokey (1983) and Chari et al. (1994). The optimal labor tax depends only on the multiplier 
on the implementability constraint $\Phi$, a measure of fiscal tightness, and the elasticities $\varepsilon_{i j}, i, j=$ $c, L$. This is a strong result and depends, as the optimal subsidy result in proposition 2 , on the completeness of the tax system.

\subsection{Optimal expansion of varieties and the profit tax}

Consider now the optimality condition with respect to R\&D investment $S_{t}\left(h^{t}\right), t \geq 0$ :

$$
\lambda_{t}=\eta \mu_{t} \vartheta_{t}+\underbrace{\Phi u_{c t}}_{\text {effect on surplus }}-(1-\eta) \frac{u_{c t}}{S_{t}}[\underbrace{\left[\rho_{t}-\rho_{t-1} \frac{\vartheta_{t-1}}{\vartheta_{t}}(1-\delta)\right.}_{\text {effect on (24) through } \vartheta_{t}} .
$$

In comparison to the respective first-best equation (28) we have two new elements. An increase in R\&D investment relaxes the government budget (because it decreases aggregate dividends and therefore it increases the surplus). Furthermore, due to the sensitivity of marginal rate of transformation $\vartheta_{t}$ to the research intensity, the current cost of entering the market is affected. This affects both current entry and entry at $t-1$, which is based on the expectation of current profits. The last term in (47) captures these effects. Using lemma 1, we get

$$
\lambda_{t}=\eta \mu_{t} \vartheta_{t}+\eta \Phi u_{c t}, t \geq 1
$$

Having the relationship between the shadow value of investment in $R \& D$ and the shadow value of output, allows ut to derive the optimal expansion of varieties prescribed by a Ramsey planner.

Proposition 4. ("Optimal growth at the second-best") The optimal accumulation of varieties is governed by

$$
1=E_{t} \Lambda_{t+1}^{\star} R_{t+1}^{s o c}, t \geq 1
$$


where $\Lambda_{t+1}^{\star}=\beta \lambda_{t+1} / \lambda_{t}$, where $\lambda_{t}$ the second-best multipliers on the resource constraint (44), and $R_{t+1}^{s o c}$ the social return to a new variety, defined in (31).

Proof. See Appendix.

Note that the discrepancies at the new variety margin between the market equilibrium (pricing condition (24)) and the Ramsey equilibrium (condition (49)) consist in pricing different returns $\left(R_{t+1}^{R D}\right.$ versus $\left.R_{t+1}^{s o c}\right)$ and using different discount factors $\left(\Lambda_{t+1}\right.$ versus $\left.\Lambda_{t+1}^{\star}\right)$. The Ramsey discount factor incorporates the effects of distortionary taxation whereas the stochastic discount factor does not. The profit tax can capture both of these effects.

Proposition 5. ("Ramsey profit tax") The profit tax is

$$
\tau_{t+1}^{\pi}=\frac{E_{t}\left(\Lambda_{t+1}-\Lambda_{t+1}^{\star}\right) \vartheta_{t+1}^{-1}\left(1-\delta+\vartheta_{t+1} \Pi_{t+1}\right)}{E_{t} \Lambda_{t+1} \Pi_{t+1}}+\frac{E_{t} \Lambda_{t+1}^{\star} \Pi_{t+1}\left[\eta \frac{g_{t+1}}{(1-\alpha) Y_{t+1}}+(1-\eta)\left(1-\frac{S_{t+1}}{(1-\alpha) Y_{t+1}}\right)\right]}{E_{t} \Lambda_{t+1} \Pi_{t+1}}, t \geq 1
$$

The first term in (50) captures the effects of the lack of lump-sum taxes on taxing the intertemporal margin, through the difference $\Lambda_{t+1}-\Lambda_{t+1}^{*}$, whereas the second term the difference between the private and social returns due to externalities and wasteful government expenditures. ${ }^{3}$ The second term would be identically zero if $\eta=1$ and $g_{t} \equiv 0$.

The requirements for a balanced growth path place restrictions on the utility function $u$ and therefore on the Ramsey discount factor $\Lambda_{t+1}^{\star}$. Consider the following two classes of preferences:

Corollary. 1. Assume separable logarithmic preferences, $u=\ln c-v(L)$. Then,

$$
\begin{aligned}
\Lambda_{t+1} & =\Lambda_{t+1}^{\star}=\beta\left(\frac{c_{t+1}}{c_{t}}\right)^{-1}, \forall t \geq 1 \\
\tau_{t+1}^{\pi} & =E_{t} \zeta_{t+1}\left[\eta \frac{g_{t+1}}{(1-\alpha) Y_{t+1}}+(1-\eta)\left(1-\frac{S_{t+1}}{(1-\alpha) Y_{t+1}}\right)\right]
\end{aligned}
$$

with positive weights that integrate to unity, $\zeta_{t+1} \equiv \frac{\Lambda_{t+1} \Pi_{t+1}}{E_{t} \Lambda_{t+1} \Pi_{t+1}}>0$.

\footnotetext{
${ }^{3}$ The first term of the formula corresponds to the formula for capital taxation in environments with exogenous growth, if we replace profits with the marginal product of capital. See Karantounias (2013) for details.
} 
2. Assume balanced growth preferences as in Chari et al. (1994),

$$
u=\frac{\left(c^{1-\gamma}(1-L)^{\gamma}\right)^{1-\psi}}{1-\psi}
$$

Then, $\Lambda_{t+1} \neq \Lambda_{t+1}^{\star}$. At the deterministic balanced growth path we have $\Lambda=\Lambda^{\star}$ and the profit tax becomes a weighted average that depends on the balanced growth path shares of government consumption and investment in RED in net output,

$$
\tau^{\pi}=\eta \times \frac{g}{(1-\alpha) Y}+(1-\eta) \times\left[1-\frac{S}{(1-\alpha) Y}\right]
$$

Proof. See the Appendix for the proof of proposition 5 and the corollary.

Note the resemblance of the result above with the results on capital taxation in environments with exogenous growth as in Chari et al. (1994), Zhu (1992) and in the classic contributions of Chamley (1986) and Judd (1985). In the event of zero externalities and zero government expenditures, we recover the zero profit tax result for either $t \geq 2$ (for the logarithmic preferences) or at the steady state (for the preferences in (51)).

\section{Numerical results}

In this section, we present a calibrated version of our model and highlight the main trade-offs active in the economy. We then describe the main dynamics of the model and run a welfare analysis. 


\subsection{Calibration and Solution Methods}

\subsubsection{Functional Forms}

In order to calibrate the model and assess its quantitative implications, we need to pick the functional forms in our specification. We adopt the balanced growth preferences in (51), where $\psi$ the coefficient of relative risk aversion in the consumption bundle, and $\gamma$ the relative weight of leisure in the utility kernel.

Exogenous shocks are mean reverting and stationary, that is, we have

$$
\log \left(z_{t}\right)=\rho \log \left(z_{t-1}\right)+\epsilon_{t}, \epsilon_{t} \stackrel{i i d}{\sim} N\left(0, \sigma^{2}\right)
$$

The absence of an exogenous drift in productivity emphasizes that in this model, growth is sustained endogenously by the accumulation of varieties.

Finally, government expenditures are specified as $\kappa_{t}=\frac{1}{1+e^{-G_{t}}}$ where

$$
G_{t}=\left(1-\rho_{G}\right) \bar{G}+\rho_{G} G_{t-1}+\epsilon_{G, t}, \epsilon_{G, t} \stackrel{i i d}{\sim} N\left(0, \sigma_{G}^{2}\right)
$$

\subsubsection{Calibration}

We summarize our quarterly calibration in table 1 . Both the relative risk aversion coefficient and the subjective discount factor are set to values well within the typical range adopted with CRRA preferences. The weight assigned to leisure in the consumption bundle is set to have a share of hours worked of $30 \%$, consistent with the data.

On the technology side, our calibration is inspired by Comin and Gertler (2006) and Kung and Schmid (2015). The share of intermediate inputs in output, $\alpha$, is set to $30 \%$; the annual depreciation of patents is $4 \%$. The congestion elasticity parameter is smaller than one and it introduces diminishing returns from $R \& D$, similarly to a convex adjustment cost function (Jermann (1998)). The scale parameter $\chi$ is calibrated in a residual fashion in order to have an average annual growth rate as close as possible to $2 \%$ under the first best.

The exogenous forces in our model are the productivity shocks and the government ex- 
TABLE 1: Benchmark Calibration

\begin{tabular}{lcc}
\hline \hline Parameter & Symbol & Value \\
\hline Preferences: & & \\
Subjective Discount Factor & $\psi$ & 0.99 \\
Relative Risk Aversion & $\gamma$ & 5.00 \\
Weight on Leisure & $\alpha$ & 0.83 \\
Technology: & $\chi$ & \\
Patent Capital Income Subshare & $\eta$ & 0.30 \\
Patent Capital Congestion, Scale Parameter & $(1-\delta)$ & 0.16 \\
Patent Capital Congestion, Elasticity & & 0.80 \\
Patent Survival Rate & $\sigma$ & 0.99 \\
Exogenous Processes: & $\rho$ & 0.02 \\
Productivity Shock, Volatility & $\bar{G}$ & 0.97 \\
Productivity Shock, Persistence & $\sigma_{G}$ & -4.25 \\
Average Expenditure Parameter & $\rho_{G}$ & 0.02 \\
Expenditure Shock, Volatility & & 0.98 \\
Expenditure Shock, Persistence &
\end{tabular}

Notes: This table reports our benchmark quarterly calibration.

penditure shocks. Both processes are calibrated to replicate key features observed in the data (as an example, see Croce et al. (2012)). Specifically, the government expenditure process is modeled so that the government expenditure-to-GDP ratio evolves as in US aggregate data. Aggregate productivity evolves such that consumption and production resemble the US data.

Given these parameters, we use perturbation methods to solve our system of equations. We compute an approximation of the second order of our policy functions using the dynare++ package. This approximation accounts for the effect of volatility on the intercept of all policy functions.

\subsection{First-Best Analysis}

In table 2, we report the implied steady state values of our main variables of interest under the first best. Since two tax margins are required to replicate the first best, we also look at the special case in which we remove one of them. Specifically, we assume the government has access to lump sum taxation to finance a production subsidy designed to overcome the distortion originated by monopoly power. In this second setting profits are not taxed.

We note that without profit taxation there is too much investment in innovation. Specifi- 


\section{TABLE 2: First-Best Steady State Analysis}

\begin{tabular}{rrrrrrr}
\hline \hline & C/GDP & S/GDP & G/GDP & Labor & $\Delta A$ & $\Delta$ Wel fare \\
\cline { 2 - 7 } First-Best & 47.49 & 41.61 & 10.90 & 30.88 & 2.01 & \\
Lump+Prod & 36.99 & 53.77 & 9.24 & 36.44 & 4.40 & -1.71 \\
\hline
\end{tabular}

Notes: This table reports the deterministic steady states of both the First-Best and the Lump-Sum Taxation plus Production Subsidy (Lump+Prod) models. C/GDP is the consumption-to-GDP ratio, S/GDP is the R\&D investment-to-GDP ratio, and G/GDP is the government expenditure-to-GDP ratio. $\Delta A$ is the annualized percentage growth rate of the economy on the balanced growth path. $\Delta$ Welfare is the percentage loss in welfare from the Lump-Sum Taxation plus Production Subsidy model compared to the First-Best.

cally, since aggregate R\&D congestion is not fully taken into account by the individual innovators, the absence of a profit tax produces over-investment in R\&D and excessive growth. Even though the economy grows at a rate twice as large as that of the first best, welfare declines by $1.71 \%$ of life-time consumption bundle. This is the result of both a lower consumption-to-GDP share and a lower share of hours devoted to leisure.

In table 3, we report a comprehensive list of simulated moments resulting from these two tax settings. Most of these moments differ slightly across tax systems and are relevant mainly for our comparison with the second best setting. We highlight a well-known result: with timeadditive CRRA preferences, it is impossible to obtain a significant risk premium with Gaussian shocks. As a result, the only way in which we can obtain a realistic cost of capital of about $8 \%$ per year is by exaggerating the average risk-free rate. We note that the quarterly risk-free rate at the deterministic steady state, $\log \bar{R}^{f}=-\log \beta+[(\psi-1)(1-\gamma)+1] \overline{\Delta c}$, depends on the relative risk aversion with respect to the consumption commodity and hence is affected by an additional $(\psi-1)(1-\gamma) \approx 0.7$ of consumption growth.

Since time-additive preferences are not particularly sensitive to small Gaussian shocks, the discrepancies between the deterministic steady state and the one that accounts for uncertainty are small. As a result, the over-accumulation of patents depresses welfare by $1.73 \%$ when profits are not taxed. This number is very close to its deterministic counterpart.

In order to better compare the behavior of macroeconomic aggregates under the first best and the case of no profit tax, we find it convenient to look at the impulse response functions implied by these two settings. The responses are depicted in figure 1 with respect to both 
TABLE 3: First-Best Moments

\begin{tabular}{lrrrrrrr}
\hline \hline & \multicolumn{3}{c}{ First-Best } & & \multicolumn{3}{c}{ Lump + Prod } \\
\cline { 2 - 4 } \cline { 6 - 7 }$\Delta y$ & Mean & SD & ACF $(1)$ & & Mean & SD & ACF $(1)$ \\
\cline { 2 - 3 }$\Delta$ & 2.01 & 2.30 & -0.01 & & 4.40 & 2.18 & 0.00 \\
$\Delta c$ & 2.01 & 1.46 & 0.00 & & 4.40 & 1.44 & 0.01 \\
$\Delta s$ & 2.01 & 3.88 & -0.01 & & 4.40 & 3.06 & 0.00 \\
$E_{t}\left[\Delta c_{t+1}\right]$ & 2.01 & 0.02 & 0.97 & & 4.41 & 0.03 & 0.97 \\
Labor & 30.88 & 0.37 & 0.97 & & 36.45 & 0.36 & 0.97 \\
$R^{f}$ & 7.43 & 0.12 & 0.97 & & 11.50 & 0.16 & 0.97 \\
$R^{r d}$ & 7.44 & 0.84 & 0.06 & & 11.51 & 0.69 & 0.11 \\
$R^{r d}-R^{f}$ & 0.01 & 0.83 & 0.00 & & 0.01 & 0.67 & 0.01 \\
$\Delta$ Welfare & & & & -1.73 & & \\
\hline
\end{tabular}

Notes: This table reports summary moments from a long simulation path for both the First-Best and the Lump-Sum Taxation plus Production Subsidy (Lump+Prod) models. Growth rates and returns are presented in annualized percentages. $\Delta y$ is output growth, $\Delta c$ is consumption growth, $\Delta s$ is $R \& D$ investment growth, $E_{t}\left[\Delta c_{t+1}\right]$ is expected consumption growth, Labor is the percent of time worked, $R^{f}$ is the risk-free rate, $R^{r d}$ is the return to R\&D investment, $R^{r d}-R^{f}$ is the excess return to $R \& D$ investment, and $\Delta$ Welfare is the percentage decrease in welfare from the Lump+Prod model compared to the First-Best.

a positive productive shock (left panels) and an adverse positive expenditure shock (right panels).

When an unexpected positive productivity realizes, the economy immediately expands, as it is optimal to work more and increase production. Going forward, agents expect lower growth of measured GDP, just because of mean reversion in both productivity and R\&D investment. Consumption growth instead, increases as it supported by a slow de-cumulation of stock of patents.

These results are standard in a Romer (1990) model of endogenous growth. Our analysis, however, shows a novel result on expected growth following a positive productivity shock. Specifically, in a model with congestion and no profit tax, expected consumption growth can fluctuate much more than under the first best. At the optimum, profit taxation should be reduced to support more investment, i.e., the slow down of investment growth should be mitigated with a tax cut and hence the response of expected consumption growth should be less severe.

Turning our attention to expenditure shocks, we see that they produce a contemporaneous 

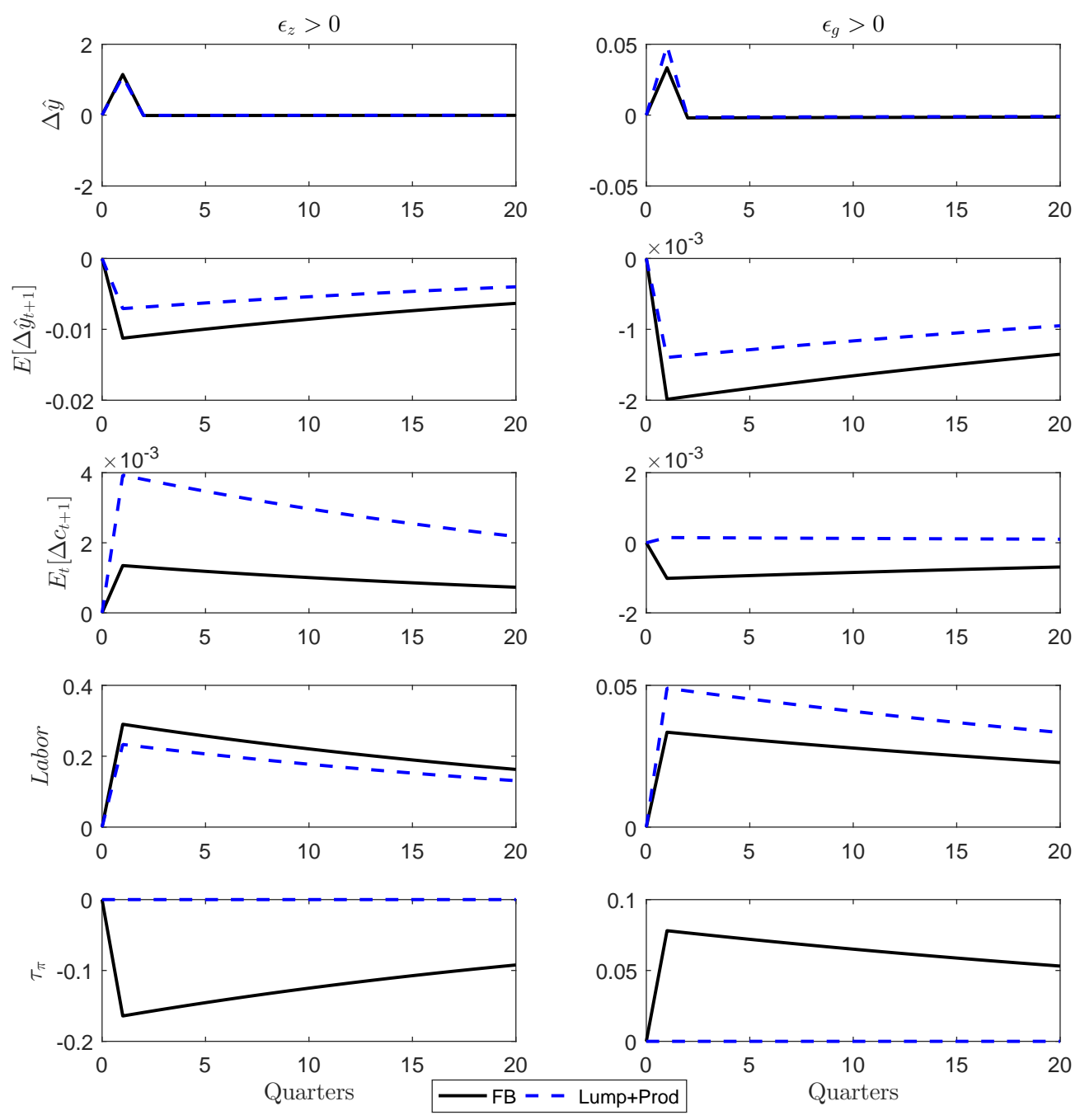

FIG. 1: First-Best Impulse Response Functions

Notes - This figure shows the impulse responses of the First-Best (FB) and the Lump-Sum Taxation plus Production Subsidy (Lump+Prod) models to positive one standard deviation shocks to the technology $\left(\epsilon_{z}\right)$ and government expenditure $\left(\epsilon_{g}\right)$ processes. Responses are shown in quarterly percentage deviations from the stochastic steady state. $\hat{y}$ represents GDP.

expansion of measured GDP as seen for productivity shocks. Since expenditure is unproductive, these shocks produce an adverse income effect that stimulates labor supply and hence production.

In the aftermath of the unexpected expenditure shock, however, expected consumption growth should decline under the first best. To better understand this result, recall that we anchor government expenditure to the size of the stock of patents. Hence in order to minimize waste it is optimal to temporarily reduce the growth of the economy and wait for the expen- 
diture shock to dissipate. This outcome can be achieved by persistently increasing the profit tax upon the arrival of an adverse expenditure shock. Absent this margin, we have a slight increase in expected consumption growth resulting from suboptimal excessive labor.

\subsection{Second-Best}

We now turn our attention to the second-best and compare results across two different values of $\Phi$. Specifically, we consider both a low $(\Phi=0.05)$ and a high value $(\Phi=0.45)$ in order to assess the relevance of the time- 0 tightness of the government budget constraint. We set the high value of $\Phi$ so that the implied average labor tax rate is 35\%, a number high enough to capture a situation of strong fiscal tightness.

In table 4 , we focus on the second-best deterministic steady state and compare it to the first-best one. The top panel refers to our benchmark calibration. In this class of models, distortionary labor taxation depresses labor and endogenously reduces both the consumption-toGDP share and the growth rate of the economy. As a result, when $\Phi=0.45$ the relative welfare loss from the first best can become as severe as $2.05 \%$. Even though the share of consumptionto-GDP declines by about 50 basis points, the implied decline of long-term growth from $2 \%$ to $0.43 \%$ is significant and highlights very well the connection between sluggish growth and fiscal tightness.

At the second-best the tax revenue from labor income (profits) as share of GDP equals the labor (profit) tax rate. When $\Phi$ is high, the total government inflow is about $58 \%$ of GDP. The labor income tax flow is the major source of revenue, as in the data. Given that the total production subsidy is equal to $100 \%$ of GDP and that the government expenditure share of GDP is $14.7 \%$, the government finds it optimal to run a primary deficit as high as $56.46 \%$ of GDP.

When $\Phi$ is low, instead, the government finds it optimal to use the profit tax as the main source of revenue and run an even more severe deficit. At a broader level, these results suggest that the debate on the relative magnitude of profit and labor taxes cannot be disconnected from the joint analysis of the tightness of both the government budget constraint and the labor 
TABLE 4: Second-Best Steady State Analysis

\begin{tabular}{|c|c|c|c|c|c|c|c|c|c|c|c|c|}
\hline & \multicolumn{6}{|c|}{ Percent of GDP } & \multirow[b]{2}{*}{ Labor } & \multirow[b]{2}{*}{$\Delta A$} & \multicolumn{3}{|c|}{ Tax Rates } & \multirow[b]{2}{*}{$\Delta W$} \\
\hline & $\mathrm{C}$ & $S$ & $\mathrm{G}$ & LR & PTR & Deficit & & & $\tau^{L}$ & $\tau^{x}$ & $\tau^{\pi}$ & \\
\hline & \multicolumn{12}{|c|}{ Panel A: Baseline $(\eta=0.80)$} \\
\hline First-Best & 47.49 & 41.61 & 10.90 & - & - & - & 30.88 & 2.01 & 0.00 & 70.00 & 20.40 & \\
\hline Low $\Phi$ & 47.43 & 41.16 & 11.41 & 6.42 & 20.89 & 84.10 & 29.50 & 1.74 & 6.42 & 70.00 & 20.89 & -0.05 \\
\hline \multirow[t]{2}{*}{ High $\Phi$} & 47.00 & 38.31 & 14.69 & 34.13 & 24.09 & 56.46 & 22.91 & 0.43 & 34.13 & 70.00 & 24.09 & -2.05 \\
\hline & \multicolumn{12}{|c|}{ Panel B: Lower Patent Accumulation Externality $(\eta=0.90)$} \\
\hline First-Best & 46.24 & 43.06 & 10.70 & - & - & - & 31.45 & 0.71 & 0.00 & 70.00 & 15.33 & \\
\hline Low $\Phi$ & 46.28 & 42.50 & 11.22 & 6.45 & 15.84 & 88.92 & 30.01 & 0.46 & 6.45 & 70.00 & 15.84 & -0.06 \\
\hline High $\Phi$ & 46.56 & 38.87 & 14.58 & 34.10 & 19.23 & 61.25 & 23.09 & -0.75 & 34.10 & 70.00 & 19.23 & -2.16 \\
\hline
\end{tabular}

Notes: This table reports the deterministic steady states for the Second-Best models under two calibrations of increasing lifetime government constraint (Low $\Phi$ and High $\Phi$ ), as well as for the First-Best. Panel A reports results under our baseline calibration and Panel B reports results when we increase the patent congestion elasticity parameter to $\eta=0.90$. Consumption $(C), R \& D$ investment $(S)$, government expenditures $(G)$, labor revenue (LR), profit tax revenue (PTR), and government deficit (Deficit) are presented as a percentage of GDP. Labor is the percent of time worked. $\Delta A$ is the annualized percentage growth rate of the economy on the balanced growth path. The labor tax $\left(\tau^{L}\right)$, production subsidy $\left(\tau^{x}\right)$, and profit tax $\left(\tau^{\pi}\right)$ rates are in percentages. The First-Best tax rates are from the tax policies necessary to implement the First-Best in a market economy with lump-sum taxation. $\Delta W$ is the percentage loss in welfare from the two Second-Best models compared to the First-Best.

market of interest to R\&D firms.

In the bottom panel of table 4 we show results for the case in which $\eta=0.90$. All other parameters are kept at their benchmark value. Consistent with the results highlighted in our previous sections, the extent of profit taxation is crucially driven by the externality in the accumulation of patents. Specifically, when we increase $\eta$ from 0.80 to 0.90 , the optimal level average level of profit taxation declines by about 500 basis points under the first-best. That is, the average profit tax declines from $20.40 \%$ to $15.33 \%$. A similar decline is observed also across second-best scenarios.

We report simulated moments from our second-best setting in table 5 . The top portion of this table considers a scenario with both productivity and expenditure shocks. The bottom panel, instead, focuses on the case in which productivity shocks are null. Consistent with prior analysis, productivity shocks are a dominant source of aggregate fluctuations, regardless of the value of $\Phi$.

We now examine the impulse response functions of the second best models. The right 
TABLE 5: Second-Best Moments

\begin{tabular}{lrccccc}
\hline \hline & \multicolumn{3}{c}{ Low $\Phi$} & & \multicolumn{3}{c}{ High $\Phi$} \\
\cline { 2 - 4 } & Mean & SD & ACF $(1)$ & Mean & SD & ACF $(1)$ \\
\cline { 2 - 5 }$\Delta y$ & & & Panel A: All Shocks & & \\
$\Delta c$ & 1.77 & 2.30 & -0.03 & 0.46 & 2.42 & -0.04 \\
$\Delta s$ & 1.77 & 1.46 & -0.03 & 0.46 & 1.56 & -0.03 \\
$E_{t}\left[\Delta c_{t+1}\right]$ & 1.77 & 3.93 & -0.04 & 0.46 & 4.42 & -0.04 \\
Labor & 1.77 & 0.01 & 0.97 & 0.46 & 0.03 & 0.97 \\
$\tau^{L}$ & 29.54 & 0.34 & 0.97 & 22.95 & 0.31 & 0.97 \\
$\tau^{x}$ & 6.42 & 0.02 & 0.97 & 34.13 & 0.07 & 0.97 \\
$\tau^{\pi}$ & 70.00 & 0.00 & - & 70.00 & 0.00 & - \\
Deficit/GDP & 20.90 & 0.69 & 0.97 & 24.16 & 0.59 & 0.98 \\
$\Delta$ Welfare & 84.09 & 0.16 & 0.01 & 56.46 & 0.58 & 0.92 \\
& -0.05 & & & -2.05 & & \\
& & & & & & \\
$\Delta y$ & & & Panel B: No Technology Shocks & & \\
$\Delta c$ & 1.74 & 0.07 & 0.00 & 0.43 & 0.10 & -0.01 \\
$\Delta s$ & 1.74 & 0.03 & 0.14 & 0.43 & 0.03 & 0.27 \\
$E_{t}\left[\Delta c_{t+1}\right]$ & 1.74 & 0.23 & -0.03 & 0.43 & 0.32 & -0.03 \\
Labor & 1.74 & 0.01 & 0.98 & 0.43 & 0.01 & 0.98 \\
$\tau^{L}$ & 29.51 & 0.05 & 0.98 & 22.92 & 0.06 & 0.98 \\
$\tau^{x}$ & 6.42 & 0.00 & 0.98 & 34.13 & 0.01 & 0.98 \\
$\tau^{\pi}$ & 70.00 & 0.00 & - & 70.00 & 0.00 & - \\
Deficit/GDP & 20.93 & 0.40 & 0.98 & 24.14 & 0.58 & 0.98 \\
$\Delta$ Welfare & 84.10 & 0.09 & 0.04 & 56.47 & 0.12 & 0.09 \\
\hline & -0.05 & & & -2.05 & & \\
\hline
\end{tabular}

Notes: This table reports summary statistics from a long simulation path for the Second-Best models under two calibrations of increasing lifetime government constraint (Low $\Phi$ and High $\Phi$ ). Panel A presents statistics when the model has been solved and simulated subject to both the exogenous technology and government expenditure shocks. Panel B presents statistics when the model has been solved and simulated subject to only the government expenditure shocks. We report the mean, standard deviation, and autocorrelation at the first lag of the simulated model paths. Growth rates are presented in annualized percentages. $\Delta y$ is output growth, $\Delta c$ is consumption growth, $\Delta s$ is R\&D investment growth, $E_{t}\left[\Delta c_{t+1}\right]$ is expected consumption growth, and Labor is the percent of time worked. The labor tax $\left(\tau^{L}\right)$, production subsidy $\left(\tau^{x}\right)$, and profit tax $\left(\tau^{\pi}\right)$ rates are in percentages. Deficit/GDP is the government's deficit as a ratio of GDP. $\Delta$ Welfare is the percentage decrease in welfare from the Second-Best models compared to the First-Best.

column panels in figures 2 and 3 confirm that expenditure shocks tend to have a modest impact on aggregate variables. Consistent with what we noted when studying the first best, upon the arrival of an adverse expenditure shock the government finds it optimal to increase profit taxes in order to slow down intangible capital accumulation and therefore waste. Under the second 

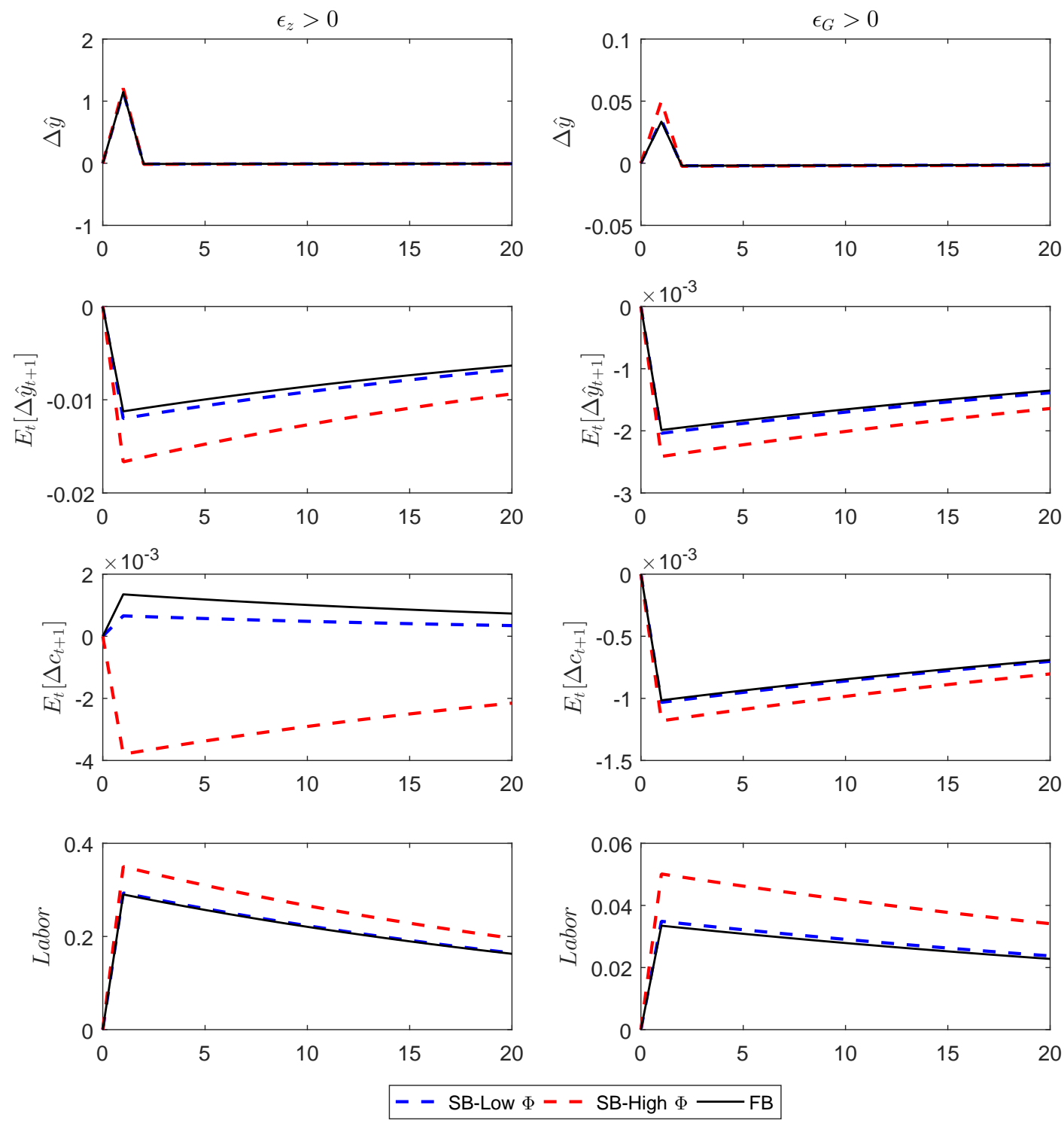

FIG. 2: Second-Best Impulse Response Functions (I)

Notes - This figure shows the impulse responses of the Second-Best models under two calibrations of increasing lifetime government constraint (SB-Low $\Phi$ and SB-High $\Phi$ ), as well as for the First-Best $(\mathrm{FB})$, with respect to positive one standard deviation shocks to the technology $\left(\epsilon_{z}\right)$ and government expenditure $\left(\epsilon_{g}\right)$ processes. Responses are shown in quarterly percentage deviations from the stochastic steady state. $\hat{y}$ represents GDP.

best, this first-best reaction is amplified and enhanced by higher values of $\Phi$.

The most interesting result, however, pertains to the optimal response of the labor tax rate. When $\Phi$ is high, the government should cut the labor tax both when productivity is subject to a positive shock and public expenditure suddenly increases. 

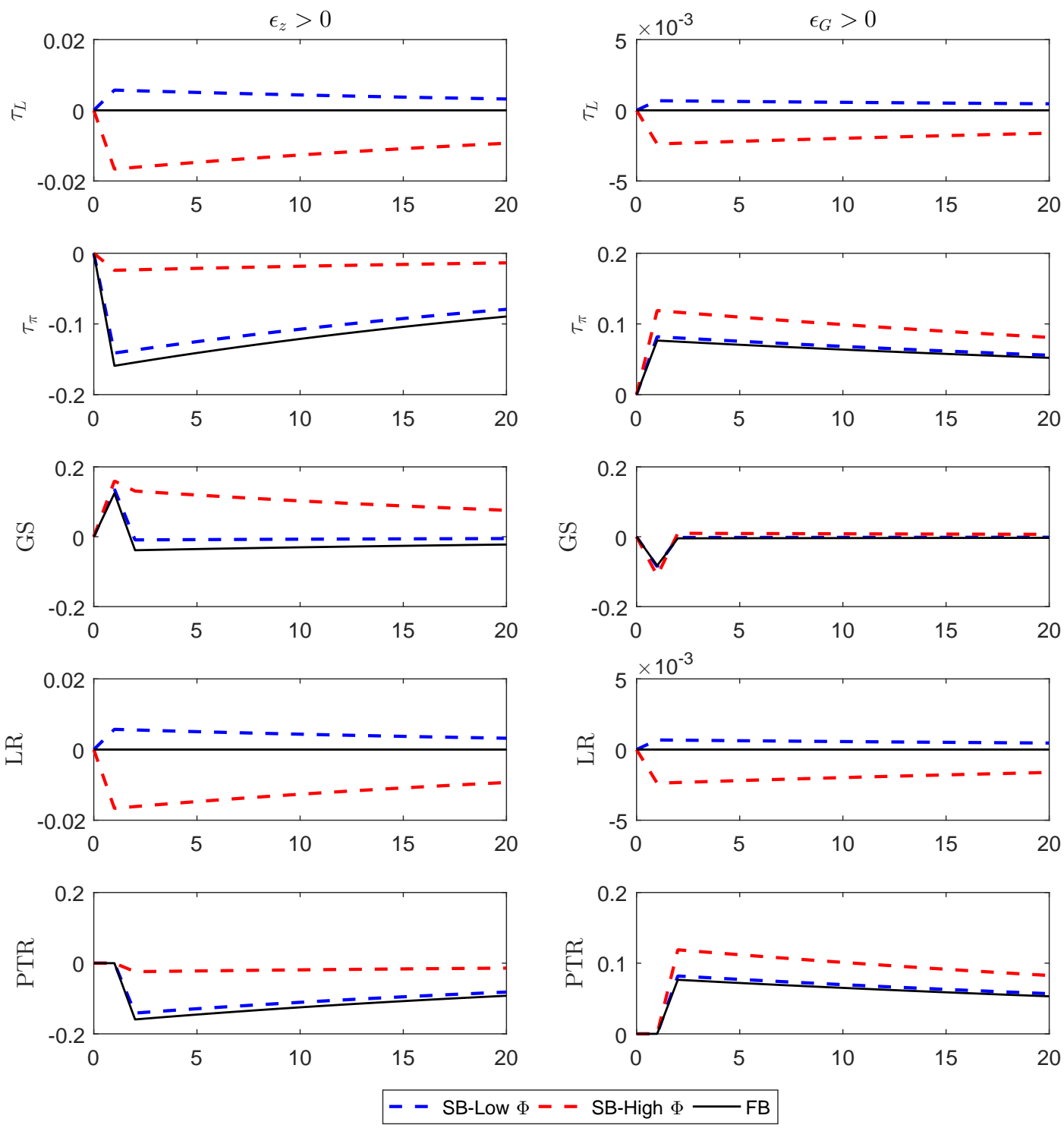

FIG. 3: Second-Best Impulse Response Functions (II)

Notes - This figure shows the impulse responses of the Second-Best models under two calibrations of increasing lifetime government constraint (SB-Low $\Phi$ and SB-High $\Phi$ ), as well as for the First-Best (FB), with respect to positive one standard deviation shocks to the technology $\left(\epsilon_{z}\right)$ and government expenditure $\left(\epsilon_{g}\right)$ processes. Responses are shown in quarterly percentage deviations from the stochastic steady state. GS denotes government surplus-to-GDP; LR refers to labor income revenue-to-GDP; and PTR represents profit tax revenue-to-GDP.

When the government faces a looser budget constraint at time-0, i.e., when $\Phi=0.05$, the government should do the exact opposite. As a result, the government should take advantage of positive productivity shocks in order to collect more labor income revenue and finance a relatively more generous profit tax cut, consistent with the prescription of the first-best. 
Given these considerations, the following remarks apply. When $\Phi$ is low, the government manipulates the labor and profit tax rates in such a way that it stabilizes the government's deficit. That is, the deficit-to-GDP ratio features modest volatility and almost no persistence. In contrast, when $\Phi$ is high, persistent productivity shocks should be associated with persistent and pronounced fluctuations of deficit-to-GDP. As reported in table 5, when $\Phi=0.45$ and all shocks are active, the persistence of the deficit-to-GDP ratio can be as high as 0.92 .

\subsection{Welfare Analysis and Sensitivity}

We conclude this section by comparing welfare results across different fiscal settings and shock configurations. In the first column of table 6 , we report the welfare losses incurred when there are no shocks and we move away from the first best either because we abstract away from the profit tax (second row), or because we are in a second-best scenario with high $\Phi$ (last row). The next three columns show the same computations when (i) all shocks are active; (ii) only productivity shocks are active; and (iii) the economy is affected only by expenditure shocks. Across all scenarios, the welfare loss incurred at the second best is significant and stable at $2.05 \%$ of life-time consumption, as in the previous section.

In the right panel of the same table, we compute welfare cost of uncertainty across fiscal regimes. Under the first-best, the welfare losses due to the presence of both productivity and expenditure shocks is in the order of 0.303 basis points. This modest welfare loss should not be surprising given that we employ CRRA preferences. Investigating further the origin of this cost, we note that most of it is due to government shocks, as removing government shocks alone produce a welfare gain of 0.261 basis points of life-time consumption.

Interestingly, the total welfare cost of uncertainty doubles when the government does not tax profits. In this case, uncertainty amplifies the over-investment in innovation and produces more pronounced welfare losses. Under the second best, instead, the state-contingent tax plan of the government limits the welfare losses of uncertainty; we observe values very close to those obtained under the first best. 
TABLE 6: Welfare Comparison

\begin{tabular}{|c|c|c|c|c|c|c|c|}
\hline & \multicolumn{4}{|c|}{ Welfare Loss Compared to First-Best } & & & \\
\hline & \multirow{3}{*}{$\begin{array}{c}\text { Determ. } \\
\text { Steady } \\
\text { State }\end{array}$} & \multicolumn{3}{|c|}{ Stochastic Steady State } & \multicolumn{3}{|c|}{ Basis Point Deviations } \\
\hline & & All & No & No & \multirow{2}{*}{$\begin{array}{c}\text { All Shocks } \\
\text { from DSS }\end{array}$} & \multicolumn{2}{|c|}{ From All Shocks } \\
\hline & & Shocks & Gov & Tech & & No Gov & No Tech \\
\hline First-Best & & & & & -0.303 & 0.261 & 0.042 \\
\hline Lump+Prod & -1.71 & -1.72 & -1.72 & -1.72 & -0.581 & 0.440 & 0.141 \\
\hline SB-High $\Phi$ & -2.05 & -2.05 & -2.05 & -2.05 & -0.297 & 0.251 & 0.046 \\
\hline
\end{tabular}

Notes: This table reports percentage changes in welfare compared to the First-Best (left panel), and the welfare loss in basis points of the stochastic steady state with all shocks on compared to the deterministic steady state (DSS) (right panel). In addition, the right panel contains the decomposition of this welfare loss, as we report the welfare gains of removing government expenditure shock (No Gov) or the technology shock (No Tech).

\section{Directions for future work}

There are several next steps that we would like to take, both theoretically and numerically. At first, we would like to examine the transition to the vicinity of the steady state, which, as we saw, features deficits, when the economy starts with positive debt. Second, we would like to dig deeper into the importance of the profit tax, by performing a third-best analysis where either the profit tax or the input subsidy are not available. Third, we would like to contrast our numerical results to the respective optimal taxation results without endogenous growth. Fourth, we would like to contrast our policy prescriptions with current U.S. policy. And finally, we would like to enrich our model by adding capital as an additional factor of production as in Comin and Gertler (2006) and Kung and Schmid (2015). This extension provides both a better quantitative fit and allows the analysis of the interaction of traditional capital taxation and profit taxation.

\section{Concluding Remarks}

We examine optimal Ramsey fiscal and innovation policy in a model in which growth is endogenously sustained by the entry of new innovative businesses. Our paper takes first steps towards understanding the optimal design of fiscally sustainable innovation policies in the 
aftermath of a debt burdened recession. With monopolistic rents rewarding innovation and spillovers from technological innovation, our results emphasize the relevance of profit taxes to finance appropriate subsidies. The higher the initial tax burden of the government, the more volatile are the required taxes, depressing growth and further amplifying and propagating cycles. In the context of the current debate about fiscal stimulus and innovation policies, this suggests that optimizing innovation and growth may come at the cost of endogenously higher risk. 


\section{A Ramsey problem}

\section{A.1 Lagrangian of Ramsey problem}

$$
\begin{aligned}
& L=\sum_{t=0} \beta^{t} \sum_{h^{t}} \pi_{t}\left(h^{t}\right) u\left(c_{t}\left(h^{t}\right), 1-L_{t}\left(h^{t}\right)\right)+\Phi\left\{\sum _ { t = 0 } ^ { \infty } \sum _ { h ^ { t } } \beta ^ { t } \pi _ { t } ( h ^ { t } ) \left(\Omega\left(c_{t}\left(h^{t}\right), L_{t}\left(h^{t}\right)\right)\right.\right. \\
& \left.\left.-u_{c}\left(c_{t}\left(h^{t}\right), 1-L_{t}\left(h^{t}\right)\right)\left[A_{t}\left(h^{t-1}\right)\left(1-\tau_{t}^{\pi}\left(h^{t-1}\right)\right)\left(P^{*}-1\right) X_{t}\left(h^{t}\right)-S_{t}\left(h^{t}\right)\right]\right)-u_{c 0} b_{0}\right\} \\
& -\sum_{t=0}^{\infty} \sum_{h^{t}} \beta^{t} \pi_{t}\left(h^{t}\right) \lambda_{t}\left(h^{t}\right)\left[c_{t}\left(h^{t}\right)+A_{t}\left(h^{t-1}\right) X_{t}\left(h^{t}\right)+S_{t}\left(h^{t}\right)+\kappa_{t} A_{t}\left(h^{t-1}\right)-Y_{t}\left(h^{t}\right)\right] \\
& -\sum_{t=0}^{\infty} \sum_{h^{t}} \beta^{t} \pi_{t}\left(h^{t}\right) \mu_{t}\left(h^{t}\right)\left[A_{t+1}\left(h^{t}\right)-\vartheta\left(\frac{S_{t}\left(h^{t}\right)}{A_{t}\left(h^{t-1}\right)}\right) S_{t}\left(h^{t}\right)-(1-\delta) A_{t}\left(h^{t-1}\right)\right] \\
& -\sum_{t=0}^{\infty} \sum_{h^{t}} \beta^{t} \pi_{t}\left(h^{t}\right) \rho_{t}\left(h^{t}\right)\left\{u_{c}\left(c_{t}\left(h^{t}\right), 1-L_{t}\left(h^{t}\right)\right)\right. \\
& -\beta \sum_{h_{t+1}} \pi_{t+1}\left(h_{t+1} \mid h^{t}\right) u_{c}\left(c_{t+1}\left(h^{t+1}\right), 1-L_{t+1}\left(h^{t+1}\right)\right) \cdot \vartheta\left(\frac{S_{t}\left(h^{t}\right)}{A_{t}\left(h^{t-1}\right)}\right)\left[\left(1-\tau_{t+1}^{\pi}\left(h^{t}\right)\right)\left(P^{*}-1\right) X_{t+1}\left(h^{t+1}\right)\right. \\
& \left.\left.+\frac{1-\delta}{\vartheta\left(\frac{S_{t+1}\left(h^{t+1}\right)}{A_{t+1}\left(h^{t}\right)}\right)}\right]\right\}
\end{aligned}
$$

where in order to save space, we did not explicitly write intermediate inputs and output as functions of labor and the subsidy $\tau_{t}^{x}$.

\section{A.2 Initial period optimality conditions}

To be completed.

\section{A.3 Proof of lemma 1}

1. Write the change in $\rho_{t}$ as

$$
\rho_{t}-\rho_{t-1} \frac{\vartheta_{t-1}}{\vartheta_{t}}(1-\delta)=\frac{A_{t}}{\vartheta_{t}}\left[\frac{\rho_{t} \vartheta_{t}}{A_{t+1}} \cdot \frac{A_{t+1}}{A_{t}}-\frac{\rho_{t-1} \vartheta_{t-1}}{A_{t}}(1-\delta)\right]
$$

But $\frac{\rho_{t} \vartheta_{t}}{A_{t+1}}=\frac{\rho_{t-1} \vartheta_{t-1}}{A_{t}}=\Phi$ due to (38). Thus, we have

$$
\rho_{t}-\rho_{t-1} \frac{\vartheta_{t-1}}{\vartheta_{t}}(1-\delta)=\Phi \frac{A_{t}}{\vartheta_{t}}\left[\frac{A_{t+1}}{A_{t}}-1+\delta\right]=\Phi \frac{A_{t}}{\vartheta_{t}} \vartheta_{t} \frac{S_{t}}{A_{t}}=\Phi S_{t},
$$

by using the law of motion of the mass of varieties, (8).

2. To show that the total effect is zero, use the definition of aggregate dividends, $D_{t}=$ $\left(1-\tau_{t}^{\pi}\right) A_{t} \Pi_{t}-S_{t}$, and the return on R\&D (25) and collect terms as 


$$
\begin{aligned}
\Phi D_{t}+\rho_{t}-\rho_{t-1} R_{t}^{R D} & =-\Phi S_{t}+\rho_{t}-\rho_{t-1} \frac{\vartheta_{t-1}}{\vartheta_{t}}(1-\delta)+\left(\Phi A_{t}-\rho_{t-1} \vartheta_{t-1}\right)\left(1-\tau_{t}^{\pi}\right) \Pi_{t} \\
& =-\Phi S_{t}+\Phi S_{t}+0=0
\end{aligned}
$$

by using (38) and (42).

\section{A.4 Proof of proposition 3}

Combine (44)-(45) to get

$$
\frac{u_{l t}}{u_{c t}} \cdot \frac{1-\Phi \frac{\Omega_{L t}}{u_{l t}}}{1+\Phi \frac{\Omega_{c t}}{u_{c t}}}=\frac{Y_{t}}{L_{t}}-\frac{A_{t} X_{t}}{L_{t}}
$$

Under the optimal subsidy though we have $A_{t} X_{t}=\alpha Y_{t}$. This implies that the right-hand side above is equal to the marginal product of labor, $\frac{Y_{t}}{L_{t}}-\frac{A_{t} X_{t}}{L_{t}}=(1-\alpha) \frac{Y_{t}}{L_{t}}=F_{L}$. Set now $u_{l} / u_{c}=(1-\tau) F_{L}$, use the formulas

$$
\begin{aligned}
& \frac{\Omega_{c}}{u_{c}}=1-\varepsilon_{c c}-\varepsilon_{c L} \\
& \frac{\Omega_{L}}{u_{l}}=-1-\varepsilon_{L L}-\varepsilon_{L c}
\end{aligned}
$$

and simplify to finally get (46).

\section{A.5 Proof of proposition 4}

New varieties are determined by the optimality condition with respect to $A_{t+1}\left(h^{t}\right), t \geq 0$ :

$$
\begin{aligned}
& \mu_{t}=\beta E_{t} \lambda_{t+1}\left[\frac{Y_{t+1}}{A_{t+1}}-X_{t+1}-\kappa_{t+1}\right]+\beta E_{t} \mu_{t+1}\left(1-\delta+(1-\eta) \vartheta_{t+1} \frac{S_{t+1}}{A_{t+1}}\right) \\
& -\Phi \beta E_{t} u_{c, t+1}\left(1-\tau_{t+1}^{\pi}\right) \Pi_{t+1}+(1-\eta) \beta E_{t} \frac{u_{c, t+1}}{A_{t+1}}\left(\rho_{t+1}-\rho_{t} \frac{\vartheta_{t}}{\vartheta_{t+1}}(1-\delta)\right)
\end{aligned}
$$

Use (42) to replace the last term and use condition (48) to replace the multipliers $\mu_{t}, \mu_{t}=$ $\frac{\lambda_{t}}{\eta \vartheta_{t}}-\frac{\Phi u_{c t}}{\vartheta_{t}}, t \geq 1$. Then, (A.1) becomes

$$
\begin{aligned}
& \frac{\lambda_{t}}{\eta \vartheta_{t}}-\frac{\Phi u_{c t}}{\vartheta_{t}}=\beta E_{t} \lambda_{t+1}\left[\frac{Y_{t+1}}{A_{t+1}}-X_{t+1}-\kappa_{t+1}\right]+\beta E_{t}\left(\frac{\lambda_{t+1}}{\eta \vartheta_{t+1}}-\frac{\Phi u_{c, t+1}}{\vartheta_{t+1}}\right)\left(1-\delta+(1-\eta) \vartheta_{t+1} \frac{S_{t+1}}{A_{t+1}}\right) \\
& -\Phi \beta E_{t} u_{c, t+1}\left(1-\tau_{t+1}^{\pi}\right) \Pi_{t+1}+(1-\eta) \Phi \beta E_{t} u_{c, t+1} \frac{S_{t+1}}{A_{t+1}}, t \geq 1 .
\end{aligned}
$$

Simplify and collect terms to get 


$$
\begin{aligned}
\frac{\lambda_{t}}{\eta \vartheta_{t}}= & \beta E_{t} \lambda_{t+1}\left[\frac{Y_{t+1}}{A_{t+1}}-X_{t+1}-\kappa_{t+1}\right]+\beta E_{t} \frac{\lambda_{t+1}}{\eta \vartheta_{t+1}}\left(1-\delta+(1-\eta) \vartheta_{t+1} \frac{S_{t+1}}{A_{t+1}}\right) \\
& +\frac{\Phi u_{c t}}{\vartheta_{t}}\left[1-\beta E_{t} \frac{u_{c, t+1}}{u_{c t}} R_{t+1}^{R D}\right]
\end{aligned}
$$

Use the pricing condition (24) and rewrite to get (49).

\section{A.6 Proof of proposition 5 and its corollary}

Proof of proposition. Remember that under the optimal subsidy we have $\Pi_{t}=\frac{(1-\alpha) Y_{t}}{A_{t}}=$ $\frac{Y_{t}}{A_{t}}-X_{t}$. Using this fact and remembering that $g_{t}=\kappa_{t} A_{t}$, we can rewrite the social return as

$$
R_{t+1}^{s o c}=\frac{\vartheta}{\vartheta_{t+1}}\left[1-\delta+\vartheta_{t+1} \Pi_{t+1}-\vartheta_{t+1} \Pi_{t+1}\left\{\eta \frac{g_{t+1}}{(1-\alpha) Y_{t+1}}+(1-\eta)\left(1-\frac{S_{t+1}}{(1-\alpha) Y_{t+1}}\right)\right\}\right] .
$$

Use (24) to express the profit tax as

$$
\tau_{t+1}^{\pi}=\frac{E_{t} \Lambda_{t+1} \frac{\vartheta_{t}}{\vartheta_{t+1}}\left(1-\delta+\vartheta_{t+1} \Pi_{t+1}\right)-1}{\vartheta_{t} E_{t} \Lambda_{t+1} \Pi_{t+1}}
$$

Replace unity in the numerator with (49), use the above decomposition of the social return and simplify to get (50).

Proof of corollary. As in Karantounias (2013), use (44) and the formula for $\Omega_{c} / u_{c}$ to express the difference in the two discount factors as

$$
\frac{\Lambda_{t+1}-\Lambda_{t+1}^{\star}}{\Lambda_{t+1}}=\Phi \frac{\varepsilon_{c c, t+1}+\varepsilon_{c L, t+1}-\varepsilon_{c c, t t}-\varepsilon_{c L, t}}{1+\Phi\left(1-\varepsilon_{c c, t}-\varepsilon_{c L, t}\right)} .
$$

For separable logarithmic preferences we have constant elasticities $\left(\varepsilon_{c c}=1, \varepsilon_{c L}=0\right)$, so $\Lambda_{t+1}=\Lambda_{t+1}^{\star}$ and the result follows from (50). For the balanced growth preferences (51) we have $\varepsilon_{c c}=\gamma+(1-\gamma) \psi$ and $\varepsilon_{c L}=\gamma(1-\psi) L /(1-L)$, which obviously fall in the previous category if $\psi=1$. Otherwise, the difference in the two discount factors depends on changes in equilibrium labor,

$$
\frac{\Lambda_{t+1}-\Lambda_{t+1}^{\star}}{\Lambda_{t+1}}=\Phi \frac{\gamma(1-\psi)\left[\frac{L_{t+1}}{1-L_{t+1}}-\frac{L_{t}}{1-L_{t}}\right]}{1+\Phi(1-\psi)\left(1-\gamma-\gamma \frac{L_{t}}{1-L_{t}}\right)}
$$

At the deterministic balanced growth path labor is constant and the two discount factors become constant and the same, $\Lambda=\Lambda^{\star}$. The result follows from (50). 


\section{B Welfare calculations}

We calculate welfare $\left(W_{t}\right)$ within each model as:

$$
\begin{aligned}
& W_{t}=U_{t}+\beta E_{t}\left[W_{t+1}\right] \\
& \tilde{W}_{t}=\tilde{U}_{t}+\beta E_{t}\left[\Delta A_{t+1}^{(1-\gamma)(1-\psi)} \tilde{W}_{t+1}\right]
\end{aligned}
$$

where $\tilde{U}_{t}=\frac{U_{t}}{A_{t}^{(1-\gamma)(1-\psi)}}$ and $\tilde{W}_{t}=\frac{W_{t}}{A_{t}^{(1-\gamma)(1-\psi)}}$ are the stationary versions of these variables. At time 0 we define $\phi$ such that $W_{0}=\frac{\left(u_{0} \phi\right)^{1-\psi}}{1-\psi}$, where $u_{0}$ is the consumption bundle at time 0 . Solving this expression for $\phi$ yields:

$$
\phi=\frac{\left[(1-\psi) W_{0}\right]^{\frac{1}{1-\psi}}}{u_{0}}=\frac{\left[(1-\psi) \tilde{W}_{0}\right]^{\frac{1}{1-\psi}}}{\tilde{u}_{0}}
$$

where $\tilde{u}_{0}=\frac{u_{0}}{A_{0}^{1-\gamma}}$ is the stationary version of the consumption bundle at time 0 .

Next we want to find the multiple $(\lambda)$ of the time 0 compensating consumption bundle in model 1 such that welfare is equivalent across two competing models $\left(W_{0,1}, W_{0,2}\right)$. Namely set $\lambda$ such that:

$$
\begin{aligned}
W_{0,1}(\lambda) & =W_{0,2} \\
\frac{\left(u_{0,1} \phi_{1} \lambda\right)^{1-\psi}}{1-\psi} & =\frac{\left(u_{0,2} \phi_{2}\right)^{1-\psi}}{1-\psi} \\
\lambda & =\frac{u_{0,2} \phi_{2}}{u_{0,1} \phi_{1}}
\end{aligned}
$$

The calibration and intial conditions are the same across the competing models; $A_{0}$ is identical in both models. Therefore:

$$
\begin{aligned}
& \lambda=\frac{u_{0,2} \phi_{2}}{u_{0,1} \phi_{1}} \\
& \lambda=\frac{\tilde{u}_{0,2} \phi_{2}}{\tilde{u}_{0,1} \phi_{1}}=\frac{\left[(1-\psi) \tilde{W}_{0,2}\right]^{\frac{1}{1-\psi}}}{\left[(1-\psi) \tilde{W}_{0,1}\right]^{\frac{1}{1-\psi}}}=\frac{\left[\tilde{W}_{0,2}\right]^{\frac{1}{1-\psi}}}{\left[\tilde{W}_{0,1}\right]^{\frac{1}{1-\psi}}}
\end{aligned}
$$

Finally, this implies:

$$
\log (\lambda)=\frac{1}{1-\psi} \log \left(\frac{\tilde{W}_{0,2}}{\tilde{W}_{0,1}}\right)
$$

We report $\log (\lambda)$ in the paper when welfare in each model is computed at (1) the deterministic and stochastic steady states $\left(\tilde{W}_{S S, 1}, \tilde{W}_{S S, 2}\right)$ and (2) the average of simulated paths $\left(E_{T}\left[\tilde{W}_{t, 1}\right], E_{T}\left[\tilde{W}_{t, 2}\right]\right)$. 


\section{References}

Aghion, Philippe, Ufuk Akcigit, and Jesus Fernandez Villaverde. 2013. Optimal Capital Versus Labor Taxation with Innovation-Led Growth. Working paper, University of Pennsylvania .

Akcigit, Ufuk, Douglas Hanley, and Stefanie Stantcheva. 2016. Optimal Taxation and R\&D Policies. Working paper, University of Chicago .

Atkeson, Andrew and Ariel Burstein. 2015. Aggregate Implications of Innovation Policy. Working paper, University of California Los Angeles.

Chamley, Christophe. 1986. Optimal taxation of capital income in general equilibrium with infinite lives. Econometrica 54 (3):607-622.

Chari, V. V., L. J. Christiano, and P. J. Kehoe. 1994. Optimal Fiscal Policy in a Business Cycle Model. Journal of Political Economy .

Chugh, S. K. and Fabio Ghironi. 2010. Optimal Fiscal Policy with Endogenous Product Variety .

Comin, Diego and Mark Gertler. 2006. Medium Term Business Cycles. American Economic Review 96 (3):523-551.

Croce, Max, Thien T. Nguyen, and Lukas Schmid. 2011. Fiscal Policy and the Distribution of Consumption Risk. University of North Carolina Working Paper.

. 2012. The Market Price of Fiscal Uncertainty. Journal of Monetary Economics 2011 Carnagie-Rochester-NYU Conference on Public Policy.

Diamond, Peter A. and James A. Mirrlees. 1971. Optimal Taxation and Public Production I: Production Efficiency. American Economic Review 61 (1):8-27.

Ferrière, Axelle and Anastasios G. Karantounias. 2016. Fiscal austerity in ambiguous times Federal Reserve Bank of Atlanta Working Paper.

Jermann, Urban Joseph. 1998. Asset Pricing in Production Economies. Journal of Monetary Economics 41 (2):257275.

Jones, Larry, Rodolfo Manuelli, and Peter Rossi. 1993. Optimal Taxation in Models of Endogenous Growth. The Journal of Political Economy 101 (3):485-517.

Judd, Kenneth L. 1985. Redistributive taxation in a simple perfect foresight model. Journal of Public Economics 28 (1):59-83.

Karantounias, Anastasios G. 2013. Optimal fiscal policy with recursive preferences. Mimeo, Federal Reserve Bank of Atlanta WP 2013-7.

Kung, Howard and Lukas Schmid. 2015. Innovation, Growth, and Asset Prices. The Journal of Finance 70 (3):10011037.

Lucas, Robert and Nancy Stokey. 1983. Optimal Fiscal And Monetary Policy In An Economy Without Capital. Journal of Monetary Economics 12 (10):55-93.

Melitz, Marc, Florin Bilbiie, and Fabio Ghironi. 2012. Endogenous Entry, Product Variety, and Business Cycles. The Journal of Political Economy 120 (2):304-345.

Prescott, Edward and Lee Ohanian. 2014. U.S. Productivity Growth Has Taken a Dive. The Wall Street Journal .

Romer, Paul M. 1990. Endogenous Technological Change. Journal of Political Economy 98 (5):71-102.

Zhu, Xiaodong. 1992. Optimal fiscal policy in a stochastic growth model. Journal of Economic Theory 58 (2):250-289. 